Document downloaded from:

http://hdl.handle.net/10251/137884

This paper must be cited as:

Albero Gabarda, V.; Espinós Capilla, A.; Serra Mercé, E.; Romero, ML.; Hospitaler Pérez, A. (2019). Numerical study on the flexural behaviour of slim-floor beams with hollow core slabs at elevated temperature. Engineering Structures. 180:561-573.

https://doi.org/10.1016/j.engstruct.2018.11.061

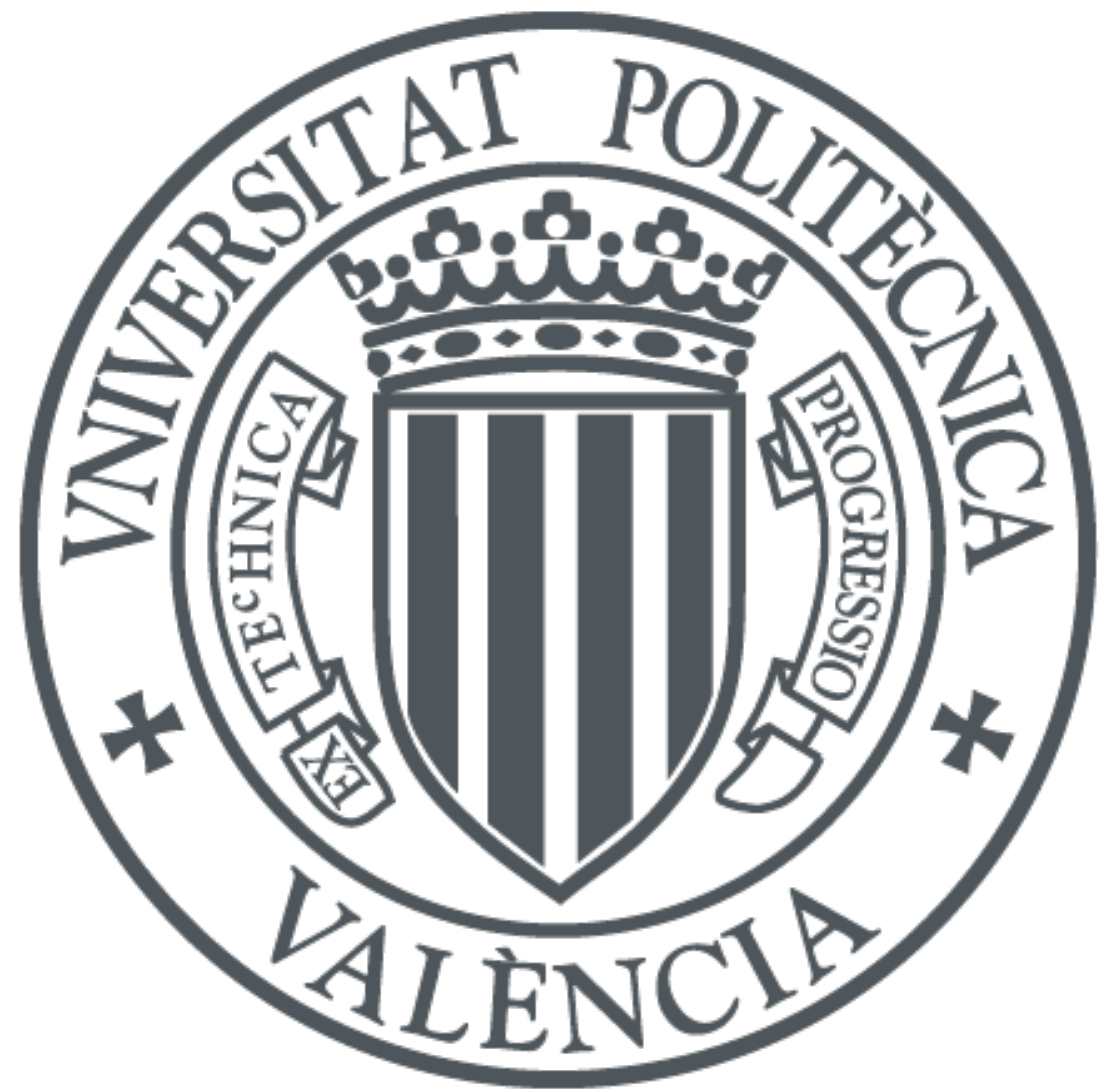

The final publication is available at

https://doi.org/10.1016/j.engstruct.2018.11.061

Copyright Elsevier

Additional Information 


\title{
Numerical study on the flexural behaviour of slim-floor beams with hollow core slabs at elevated temperature
}

\author{
V. Albero ${ }^{\text {a }}$, A. Espinós ${ }^{\text {a }}$, E. Serra ${ }^{\text {a }}$, M. L. Romero ${ }^{a^{*}}$, A. Hospitaler ${ }^{\text {a }}$ \\ ${ }^{a}$ Instituto de Ciencia y Tecnología del Hormigón (ICITECH), \\ Universitat Politècnica de València, Valencia, Spain \\ * Corresponding author. e-mail address: mromero@mes.upv.es
}

\begin{abstract}
Slim-floor beams are a novel typology of steel beams where the steel profile is fully embedded within the concrete floor depth. While the use of this system is increasing fast in the construction practice, the available investigations on its fire performance are still scarce. This paper focuses on analysing the fire behaviour of slim-floor beams combined with hollow core slabs as flooring system. Two configurations are studied, namely Integrated Floor Beam (IFB) and Shallow Floor Beam (SFB). A finite element model is developed and validated by comparison with experimental results available in the literature as well as with thermal tests carried out by the authors. Subsequently, parametric studies are conducted with the aim of providing practical design recommendations. The influence of the composite beam configuration, concrete type, longitudinal reinforcement and steel plate thickness is studied. The conclusions drawn in this paper suggest that the SFB configuration may provide a significant enhancement in terms of fire resistance compared to IFB, provided that the appropriate combination of the parameters studied is used.
\end{abstract}

Keywords: Steel-concrete composite beams, fire resistance, slim-floor, finite element model 


\section{INTRODUCTION}

One of the most common typologies of steel-concrete composite beam used in practice is the so called slim-floor beam. Increasing interest has been observed during last years in Europe related to the installation of slim-floor beams in residential and non-residential buildings. The main characteristic of this typology is that the whole height of the beam remains embedded within the floor depth. Taking advantage of this reduced height, slim-floor beams offer several improved performances such as the total floor thickness reduction and the provision of clear under-floor space for the easy installation of technical equipment.

Related to the whole floor construction, slim-floor beams can be used combined with different floor elements, such as profiled steel deck or precast concrete slabs. One of the most interesting typology is obtained from combining the slim-floor beam with precast hollow core slabs, which provides additional benefits as the fast erection and the structural efficiency for longer spans.

Currently, two different slim-floor cross-sections are available in market: the Integrated Floor Beam (IFB) which is an asymmetric I-section made from a cut hot-rolled symmetric Iprofile welded to a lower or upper steel plate and the Shallow Floor Beam (SFB) built from a hot-rolled symmetric I-section (without cutting), welded to a lower plate, see Fig. 1. The main difference between both typologies comes from the double lower flange provided by SFB compared with the single one in IFB.

Furthermore, the emphasis of this work is focused on the flexural behaviour of slim-floor beams under standard time-temperature fire curve. This aspect has been studied through some experimental campaigns performed over the last years [1-4]. Specifically, a suitable fire behaviour during the event of fire is expected due to the fact that this types of beam are exposed to fire only from their lower flange, in contrast with other composite beams, which are not totally embedded in the floor. EN 1994-1-2 [5] provides simplified models to evaluate 
temperatures in the scenario of a standard ISO-834 fire exposure for composite beams without concrete encasement (EN 1994-1-2 Clause 4.3.4.2.2) and with partial encasement (EN 1994-12 Annex F). Nevertheless, a simplified model to evaluate the temperature field in slim-floors is not available in standards.

Zaharia and Franssen [6] developed simple equations for the temperature calculation within the cross-section of IFB exposed to standard ISO-834 fire curve. This simple model provides equations to obtain the temperature of bottom plate, web and reinforcing bars embedded in concrete. The temperature of the top flange is not provided because it is assumed that it does not reach $400{ }^{\circ} \mathrm{C}$ after 120 minutes of standard fire exposure, thus retaining its full strength. After this proposal, Cajot et al. [7] and Romero et al. [8] analysed in depth the previous model and compared it against models from standards and experimental tests. More recently, a new proposal was published by Hanus et al. [9] providing a more accurate analytical model to predict the temperature of longitudinal reinforcing bars embedded in slim-floors.

The present paper is focused on the development of an advanced Finite Element Model (FEM) for the evaluation of slim-floor composite beams, mainly of SFB typology, combined with precast hollow core slab floors supported by the bottom steel plate and welded to the lower flange of the beam, see Fig. 2. This slim-floor typology has been less analysed than others using profiled steel deck, however it is receiving an increased interest by practitioners in recent years due to the high-speed erection of this system.

The FEM model presented in this paper has been validated against experimental data from bibliography [1, 2, 10-12]. Furthermore, additional thermal tests developed at Universitat Politècnica de Valencia, Spain are presented here to validate the thermal model and provide more insight into the thermal behaviour for a better understanding of this slim-floor configuration. 
Once the presented numerical model is validated, a parametric study is carried out to provide an database of results which allows for a further analysis of different parameters such as concrete aggregate type, bottom plate thickness, reinforcement or slim-floor configuration (IFB or SFB) and their influence over the fire behaviour of the slim-floor beam. Finally, based on the results of the parametric study, detailed design recommendations are provided to assist practitioners in a better use of slim-floors in fire design.

\section{DESCRIPTION OF THE NUMERICAL MODEL}

\subsection{Geometry, loading, boundary conditions and finite element mesh}

A thermo-mechanical finite element model for simulating the nonlinear behaviour of slim-floor beams in fire was developed by employing the general purpose finite element package ABAQUS [13].

The model was made up of different parts: The steel profile, the bottom steel plate, the precast concrete slab, the concrete encasement and the reinforcing bars.

The slim-floor beam was pin-ended and a transverse load was applied through an elastic loading plate, placed in L/3 (Fig. 3). Owing to symmetry of both the geometry and the boundary conditions, only a quarter of the beams was modelled, see Fig. 3. Since the flexural failure of the beam was analysed in this work, the loading plate was placed so as to produce pure bending in the critical cross-section. Besides, it can be observed in Fig. 3 that the hollow core slab holes geometry was simplified in the finite element model. They were modelled as square holes. This modelling assumption does not compromise the validity of the results and reduces importantly the mesh complexity and the computational cost. The holes are far enough to the main part of the steel beam and the variation of their geometry from round to square shape does not influence the thermal and mechanical performance of the beam. 
Particularly, for the analysis of the slim-floor in fire, two finite element models were needed: a thermal model and a mechanical model, since a sequentially coupled thermal-stress analysis was chosen as the analysis strategy. All model parts (steel profile, bottom plate, concrete encasement and reinforcements) were meshed using three-dimensional eight-noded heat transfer solid elements with nodal temperature degree of freedom (DC3D8) for the thermal analysis and three-dimensional eight-noded solid elements with reduced integration (C3D8R) in the mechanical analysis. A maximum finite element size of $20 \mathrm{~mm}$ was employed for meshing all concrete parts. Additionally, a finer mesh density (size $5 \mathrm{~mm}$ ) was used for steel elements in those parts where the thickness of the profile is more reduced, i.e. the I-profile web and flange and the bottom plate.

\subsection{Material models at elevated temperatures}

The numerical simulations took into account the temperature dependent thermal and mechanical properties of steel and concrete.

For concrete and steel, the temperature dependent thermal and mechanical properties recommended in EN 1994-1-2 [5] were adopted. Regarding to ABAQUS material models, for concrete, Concrete Damage Plasticity (CDP) model was used which allows capturing the fundamental types of failure as crushing as cracking. The parameters used for this model, following previous works from authors [14], were: $15^{\circ}$ of dilatation angle, 0.1 of eccentricity, 1.16 of initial equibiaxial to uniaxial compressive yield stress ratio and $2 / 3$ for the parameter related to the shape of the yield surface in the deviatoric plane. These parameters were not varied in terms of temperature. Additionally, damage parameters in the constitutive behaviour were included because even if the load is monotonic, some regions change from tension to compression due to thermal effects. These damage parameters take values from zero to one representing undamaged and damage material, respectively. The specific values for the damage 
parameters for tension and compression were taken from Cicekli et al. [15]. On the other hand, for steel, the isotropic multiaxial plasticity model with Von Mises yield surface was employed.

The moisture content of the concrete infill was taken into account through a peak value in the specific heat, representing the latent heat of water vaporization. A moisture content of $4 \%$ in concrete weight was considered, when experimental data was not available. Additionally, following the recommendations from previous research works [14] an increased peak value may be used to reproduce the concrete temperature plateau in the validation cases.

\subsection{Analysis procedure}

A sequentially coupled thermal-stress analysis was used to conduct the numerical simulations, thus two different models were needed: a heat transfer model and a mechanical model. The analysis was performed by first conducting a pure heat transfer analysis for computing the temperature field and afterwards a stress/deformation analysis for calculating the structural response. Nodal temperatures were stored as a function of time in the heat transfer analysis results and then read into the stress analysis as a predefined field.

\subsubsection{Thermal analysis}

A nonlinear heat transfer analysis was first conducted for each of the slim-floor beam specimens under study. The standard ISO-834 [16] fire curve was applied to the exposed surface as a thermal load, through the convection and radiation heat transfer mechanisms. The slim-floor cross-section was only exposed to fire from the lower surface along its entire length. The values recommended in EN 1991-1-2 [16] were adopted for the governing parameters of the heat transfer problem. A constant convective coefficient of $25 \mathrm{~W} / \mathrm{m}^{2} \mathrm{~K}$ was assumed for the exposed surface, while $4 \mathrm{~W} / \mathrm{m}^{2} \mathrm{~K}$ was applied in the unexposed surface, since heat radiation was taken into account separately. Related to the radiative heat flux, an emissivity value of 0.7 
was used for steel and concrete surfaces. Besides, cavity radiation was assumed in the hollow core slab holes, see Fig. 4.

The thermal resistance at the boundary between the steel bottom plate and the steel profile lower flange was considered through a gap conductance value of $100 \mathrm{~W} / \mathrm{m}^{2} \mathrm{~K}$. Moreover, a gap radiation was taken into account, following the recommendation from Fellinger and Twilt [10]. This gap radiation -which can be defined in Abaqus- allows that radiative heat transfer between closely contact surfaces occurs in the direction of the normal between the surfaces. Abaqus defines the radiative heat flux $(q)$ per unit surface area crossing the gap as follows:

$$
q=C\left(\theta_{A}^{4}-\theta_{B}^{4}\right)
$$

where $\theta_{A}$ and $\theta_{B}$ are the temperatures of the two surfaces and the coefficient $C$ is given by:

$$
C=\frac{F \sigma}{\frac{1}{\epsilon_{A}}+\frac{1}{\epsilon_{B}}-1}
$$

where $\sigma$ is the Stefan-Boltzmann constant, $\epsilon_{A}$ and $\epsilon_{B}$ are the surface emissivities assumed as 0.7 for steel- and $F$ is the view factor defined as 1.0 .

This thermal resistance between the bottom plate and the profile lower flange is proved to have an important influence over the temperature evolution along the SFB cross-section. Additionally, the thermal bowing between both elements [17] may increase the effect of the initial gap, however a mean value for the gap conductance was assumed for the whole fire exposure time. Related to the boundary surface between the steel profile and the concrete encasement a gap conductance value of $250 \mathrm{~W} / \mathrm{m}^{2} \mathrm{~K}$ was considered. In this case no gap radiation was assumed, see Fig. 4.

The results from the described nonlinear heat transfer analysis consisted of the temperature-time curves for all the nodes within the three-dimensional model, which were subsequently applied as a thermal load to the mechanical model. 


\subsubsection{Structural analysis}

A nonlinear stress analysis was subsequently conducted using the same FEA package [13], accounting for the nodal temperature-time curves previously calculated in the thermal model. The finite element meshes and the node numbering were exactly the same as those used in the thermal analysis model.

In the first step, the load was applied at room temperature through the loading plate. This load was maintained during the second step (the fire step), where the evolution of the temperature along the fire exposure time was imported from the thermal model.

The mechanical interaction between the steel and concrete infill was modelled as follows. In the normal direction, a "hard point" contact formulation was used, which allows any pressure value when the surfaces are in contact and transmits no pressure when the surfaces do not contact. For the tangent interaction, the Coulomb friction model was used, with a friction coefficient of 0.25 , following Ellobody [18] suggestion. This friction coefficient allows the composite action without modelling specific shear studs. Partial shear connection can be reproduced through this friction coefficient as it was demonstrated in the model validation which is presented in following sections. Finally, relative displacement along the welded joint between the bottom plate and steel profile was prevented by introducing a "tie" constraint.

\section{VALIDATION OF THE NUMERICAL MODEL}

The specific typology of slim-floor beams supporting hollow core slabs has not been tested in case of fire. However, enough fire tests are available in the literature related to slimfloor beams with deep composite steel deck $[2,3,11,17]$. Therefore, in the absence of specific test results and in order to validate the numerical model presented in this work in a reliable way, a sequential validation was carried out. Firstly, the hollow-core slab model at elevated temperatures was validated taking into account previous research work from the authors [14, 
19]. Secondly, the slim-floor beam model was validated by comparison with tests using composite steel deck instead of hollow core slabs. Finally, a thermal model for the specific configuration of slim-floor beams with precast hollow core slab as flooring system was validated with own tests carried out in the testing facilities of ICITECH (Concrete Science and Technology Institute) at Polytechnic University of Valencia (UPV), Spain. Also additional thermal tests from bibliography were used.

\subsection{Previous validation of the hollow-core slab model at elevated temperature}

In previous research work from the authors [14] a numerical FE model to reproduce the mechanical behaviour of hollow core slabs at elevated temperatures was presented. This FE model was validated against an experimental campaign [19] showing a good fitting, see Fig. 5. It should be highlighted that in the hollow core slab FE model, both the cavity radiation for the thermal evolution in the holes and the inclusion of the reinforcing bars prestress field along the concrete slab were taken into account. Additionally, this FE model, previously developed, showed also the good performance of Concrete Damage Plasticity (CDP) model which allows to capture the bending failure in fire. This plasticity model for concrete is implemented again in this work expecting as good response as it was shown for hollow core slabs.

Therefore, this previous FE model for hollow core slabs was a starting point for the development of the slim-floor FE model and it was used into the three-dimensional model as a part of the whole flooring system.

\subsection{Validation of the slim-floor beam with steel deck model by comparison with tests from literature}

The previously described thermo-mechanical FE model at elevated temperatures was validated against available test results on a slim-floor beam referred to as Asymmetric Slimfloor Beam (ASB), which is an alternative designation for the IFB section, with composite steel 
deck. This steel deck consists of a trapezoidal steel sheet placed transversally to the ASB/IFB beam which also works as a framework for the concrete slab. It should be noticed that this slimfloor configuration, using trapezoidal steel sheet, permits the heating of the ASB/IFB beam from 3 faces (bottom and lateral face) in contrast with slim-floor beams supporting hollow core slabs which is exposed to fire only from the bottom face.

Specifically, two standard fire tests conducted at the Warrington Fire Research Center [11] were used in this validation. The specimens tested were denoted as 280 ASB and 300 ASB, having a span of 4.5 meters. Additionally, the Finnish ASB test developed by Ma and Mäkeläinen [2] was also included, denoted as 400 ASB with $6 \mathrm{~m}$ span. The description of the test setup, the specimen geometry and the material properties for these experimental campaigns can be found in [2] and [1]. The model shows a god fitting in terms of temperature evolution and vertical displacement of the middle section, see Fig. 6 . It predicts the failure time accurately, as it can be observed in Fig. 6b. The temperature along the cross-section was validated for the 400 ASB specimen in the bottom steel plate, the web profile and the upper flange (points 1, 2 and 3 in Fig. 6b a).

\subsection{Validation of the slim-floor beam thermal model combined with hollow-core slabs}

As it was described before, there are no available fire tests of slim-floor beams with precast hollow core slabs. However, some thermal tests were carried out previously by other authors. Newman [12] published in 1995 a series of test results for SFB beams. One of these tests (test D) with concrete infill and hollow core slab is very similar to the slim-floor crosssection studied in this work. The tested specimen D consisted of a UC254 British profile welded to a bottom plate of $454 \mathrm{~mm}$ width and $15 \mathrm{~mm}$ thickness. The test and model results are shown in the Table 1. In this case, Newman [12] only provide temperatures at standard fire times and curves with temperature evolution of each cross-section element are not available. As can be seen, the temperatures obtained through the model fit well with those temperatures measured 
by Newman, except for the lower flange temperature at 30 minutes of fire exposure. However, this discrepancy was already observed in Newman's model, and should be deeply studied.

Additionally, the developed FE thermal model was validated against the test results from Fellinger and Twilt [10]. In this case, the test specimen consisted of an HEM 180 welded to a bottom plate with dimensions $400 \times 15 \mathrm{~mm}$. Fellinger and Twilt research paper [10] provides curves for the bottom plate and lower flange temperature evolution, which are compared with the developed model solution, see Fig. 7, showing a good fitting. Nevertheless, the higher temperature discrepancy between the model and test results occurs again at the lower flange at fire exposure time lower than 60 minutes. The slight discrepancy between the experimental results and model prediction observed in these tests may be solved by using a variable thermal conductance value to adjust properly the temperature evolution for the first minutes of fire exposure. As it was noticed in section 2.3.1, the thermal bowing between bottom plate and lower flange causes a variation in the thermal conductance at the gap, which is normally taken into account through a mean value along the fire history (otherwise it would require a fully coupled thermomechanical analysis).. Therefore, for the sake of simplicity in the development of the FE model, a mean value for the thermal conductance was adopted without important discrepancies.

It should be highlighted that these experiments only studied the thermal behaviour of the cross-section and time-displacement curves are not available.

In order to improve the thermal validation of the slim-floor FE thermal model and to achieve a better understanding of the thermal contact between the different cross-section parts, a set of experiments were carried out in the testing facilities of ICITECH at the Polythechnic University of Valencia, Spain. In this experimental campaign, an electrical radiative furnace was used, see Fig. 8 , reaching $800^{\circ} \mathrm{C}$ inside the furnace. The test was set up in such a way that the specimen was exposed to heat only from its lower surface. This configuration matches with the real slim-floor beam exposure in practical situations. 
Different slim-floor specimens were tested in order to validate the thermal contact between each cross-section part, see Table 2. Firstly, specimen SFB215-wC made from a HEB 200 profile welded to a bottom plate of dimensions 360x15 mm was tested without hollow core slabs or concrete encasement - only the steel parts -. In this way, the validation was focused on the definition of the thermal contact between the bottom plate and the lower flange of the steel profile. Secondly, specimen SFB215 was defined taking as reference the previous one, but including the hollow core slabs, concrete encasement and reinforcing bars. In this second specimen the validation was focused on the thermal contact between steel and concrete, while maintaining the steel-steel contact definition from the previous validation. Finally, specimen IFB255, made from a half IPE450 welded to a bottom steel plate of dimensions 360x30 mm, was tested to provide evidences about the different thermal behaviour between SFB and IFB due to the thermal contact resistance in the gap between the bottom plate and the lower flange. The detailed geometry can be seen in Fig. 9.

In order to evaluate the thermal behaviour of each specimen, up to 17 thermocouples were placed in the cross section (see Fig. 9). This configuration allows for an exhaustive analysis of the temperature evolution of each cross-section part: bottom plate, lower and upper flange, profile web, reinforcing bars, etc.

It should be noted that these tests were carried out with a heating curve different than ISO-834, since the electric furnace cannot be adjusted to follow a predefined temperature curve. It works with a long term target temperature instead, which reaches up to $800^{\circ} \mathrm{C}$. The furnace temperature evolution was registered through 4 plate thermocouples. They showed a uniform temperature field inside the furnace. The mean value of the registered temperature of these 4 plate thermocouples is shown for each experiment in Fig. 10, Fig. 11 and Fig. 12, together with the rest of the measured temperatures. 
Specifically, Fig. 10 displays the temperature evolution of thermocouples 1-4-5-6-7 placed along the vertical symmetry axis in the experimental specimen $S F B 215-w C$. The FE model accuracy is confirmed here through the good fitting shown between solid and dashed lines, which represent test and numerical results, respectively. Besides, the temperature difference between TC1 and TC4 (Fig. 10), which raises up to $100{ }^{\circ} \mathrm{C}$, reflects the effect of the thermal gap between the bottom plate and lower flange in SFB, which was thermally modeled as exposed in Section 2.3.1.

Additionally, Fig. 11 and Fig. 12 show also the good fitting of the model for SFB215 and IFB255 specimens with concrete encasement. In this case, only the thermocouples along the axis of symmetry are displayed in order to represent the temperature evolution of the steel parts, which has a strong influence over the flexural resistance of the composite beam. Moreover, the temperature evolution of the reinforcing bars is also included in this figure.

The previous validations show that the developed FE model offers an accurate prediction of the thermo-mechanical behaviour of SFB and IFB slim-floor composite beams with an average error lower than $5.00 \%$. The validation was carried out using both profiled steel deck and hollow core slabs as flooring system. However, it was noticed that the slim-floor configuration with precast concrete hollow core slab was less studied in bibliography. Therefore, the presented FE model is used hereafter to develop parametric studies that may result useful to acquire a better understanding of the fire behaviour of this type of slim-floor beams and develop design recommendations that can be useful for practitioners.

\section{THERMO-MECHANICAL BEHAVIOUR OF SLIM-FLOOR BEAMS AT ELEVATED TEMPERATURE}

In the previous section, the ability of the numerical model to capture the observed thermomechanical response of slim-floor beams with profiled steel deck has been demonstrated. Besides, the accuracy of the thermal model for cross-section configuration, such as hollow core 
slabs was also demonstrated. It should be noticed that the main difference between these configurations comes from their thermal behaviour. While steel deck permits the exposure of the slim-floor beam to fire from three sides, the configuration including hollow core slabs is exposed only from the bottom side and a void radiation should be obviously included. Therefore, once the mechanical response at elevated temperatures has been developed in the model for slim-floor beams with profiled steel deck and having demonstrated the validity of the model to capture the thermal behaviour including hollow core slabs, it can be assumed that the numerical model will also yield accurate results for the mechanical response in fire of slimfloor beams combined with hollow-core slabs.

\subsection{Parametric studies}

The following parametric studies explore the influence of varying certain geometric and material parameters such as the slim-floor configuration, bottom plate thickness, concrete aggregate type and longitudinal reinforcement. The list of parameters studied and its variation is shown in Table 3.

Following the proposal presented in Table 3, there are 8 different slim-floor configurations to be analysed. Additionally, 8 different load levels are applied to each specimen in order to obtain a complete evolution of the slim-floor beam fire behaviour under different load levels. The load levels applied are referred as a percentage of the ultimate load of the beam at room temperature, namely: 20-25-30-40-50-60-70-80\%. Therefore, the total number of numerical calculations amount 64 case analysis.

As it was explained before, the objective of the parametric study is to assess the influence of the above mentioned parameters over the fire behaviour of slim-floor beams. Thus, only one parameter is changed at a time on each specimen, while the rest remain constant.

All the analysed specimens share the following values of the fixed parameters: 
- Beam length: $6.2 \mathrm{~m}$.

- Concrete topping: $50 \mathrm{~mm}$.

- $\quad$ Load pattern: 4 points, 2 point loads applied at L/3, see Fig. 13.

- Boundary condition: Pinned-Pinned.

- Longitudinal expansion: Unconstrained.

- $\quad$ Steel yield strength: $355 \mathrm{MPa}$

- Reinforcing bars yield strength: $500 \mathrm{MPa}$

- Concrete encasement strength (cylindrical): $30 \mathrm{MPa}$.

- Precast concrete strength (cylindrical): $45 \mathrm{MPa}$.

- Tensile strength for concrete (EC2-1-1 Table 3-1): $f_{c t m}=0.3 f_{c k}{ }^{2 / 3}$

- Fire load: ISO 834 time-temperature curve.

Additionally, one of the specimens is used as a reference case for the overall analysis. It is configured as a SFB, made from a HEB 200 profile welded to a bottom plate of $400 \mathrm{~mm}$ width and $15 \mathrm{~mm}$ thickness. This configuration is a commercial solution available in the market. The reference specimen is defined without reinforcing bars and it is denoted in the following sections as SFB0.

As a preliminary step in the evaluation of each case specimen from the parametric study, the mechanical model is numerically simulated at room temperature - no temperature field applied - in order to obtain its ultimate load. This model is developed by imposing an increasing displacement at $\mathrm{L} / 3$, being $\mathrm{L}$ the span length, until the maximum reaction force is reached. The ultimate reaction force obtained for the reference specimen was $163.7 \mathrm{kN}$, which corresponds to a sagging moment capacity of $338.3 \mathrm{kN} \cdot \mathrm{m}$. Once the ultimate load at room temperature is obtained, the different load levels defined above can be applied to each specimen through the sequentially coupled thermal-stress analysis procedure described in Section 2.

Fig. 14a displays the vertical displacement of the middle section under the 8 different load levels applied, along the fire exposure time. It can be observed that different failure times 
are reached depending on the applied load level. Failure is considered to occur when the deflection limit (D) or the maximum deflection ratio (dD/dt) is reached, according to EN 1363 [20]:

$$
\begin{gathered}
D=\frac{L^{2}}{400 \cdot d}(\mathrm{~mm}) \\
\frac{d D}{d t}=\frac{L^{2}}{900 \cdot d}(\mathrm{~mm} / \mathrm{min})
\end{gathered}
$$

where $L$ is the beam span between supports (in $\mathrm{mm}$ ) and $d$ is the cross-section effective depth (in mm).

The overall behaviour of the beam in fire shows 3 stages: first, an important stiffness reduction due to thermal strains is shown by the rapid increment in the vertical displacement at low fire exposure times. On a second stage, the slope of the vertical displacement curve decreases progressively when the influence of the thermal strains is less important than the reduction of the strength of steel and concrete at elevated temperatures. Finally, the specimen reaches a failure point when the slope of the vertical displacement curve increases again and the displacement velocity rises dramatically. A practical curve, which shows the decrease of the slim-floor capacity at elevated temperatures can be obtained by matching the failure time with the load applied on each case, see Fig. 14b.

\subsubsection{Effect of the bottom plate thickness}

The first parameter studied was the bottom plate thickness. In the reference specimen (SFB0), described above, a bottom plate of $400 \mathrm{~mm}$ width and $15 \mathrm{~mm}$ thickness was used. In this first study, two additional specimens were studied using bottom plates with $10 \mathrm{~mm}$ (SFB1) and $20 \mathrm{~mm}$ (SFB2) thickness, while maintaining the same width of $400 \mathrm{~mm}$. Table 4a) shows the section factor $\left(A_{m} / V\right)$, steel cross-section area $\left(A_{s}\right)$ and inertia $\left(I_{s}\right)$ together with the ultimate load $\left(N_{R d}\right)$ and sagging moment capacity at room temperature $\left(M_{R d}\right)$. It should be explained here that the section factor for SFB beams was calculated as given in Table 4.2 of EN1993-1-2 [21]: 


$$
A_{m} / V=\left(b+2 t_{f}\right) /\left(b \cdot t_{f}\right)
$$

where $b$ is the bottom plate width and $t_{f}$ is the bottom plate thickness.

In this table, a comparison in terms of relative increase of area, inertia and room temperature capacity is given, referred to specimen SFB0.

Following the same procedure as that applied to the reference specimen SFB0, beams SFB1 and SFB2 were also calculated at room temperature, obtaining their ultimate load capacity. It can be observed in Table 4a) that the bottom plate thickness variation has not a significant influence in the ultimate load capacity at room temperature $(-0.59 \%$ and $+0.89 \%$ variation). However, more important differences are observed when time-temperature standard fire curve ISO-834 is applied, following the same loading scheme described previously, see Fig. 15. The results of the failure times obtained for the different load levels applied are given in Table 4b), where it can be observed that reducing the bottom plate thickness (SFB1) leads to a decrease in fire resistance between 9-14\%, while increasing the bottom plate thickness (SFB2) improves the fire resistance between a 6-16\%, depending on the load level studied. Obviously, this implies a higher usage of steel, since the bottom plate thickness is increased $5 \mathrm{~mm}$ with respect to the reference specimen.

Fig. 15 shows the bending capacity at different standard fire exposure times for these two specimens, together with the reference specimen from Fig. 14b. The bending capacity at elevated temperatures has been normalised, by referring it to the bending capacity of the reference specimen SFB0 at room temperature. Therefore, the figure is displayed in terms of $\left(N_{f i, E d} / N_{R d, S F B 0}\right)$. Only values lower than 0.8 are available, since this was the maximum load level applied in the fire procedure described above.

Through Fig. 15, it can be observed that specimen SFB2 with the thickest bottom plate shows a superior fire behaviour, with a curve showing higher fire resistance times for any load level. On the contrary, SFB1, with the thinnest bottom plate shows the worst fire behavior. For 
instance, for a 0.4 load level applied, SFB1 configuration shows 65 minutes of fire resistance, while SFB2 reaches a fire resistance up to 80 minutes. The improved fire performance shown by the specimen with the thickest bottom plate (SFB2) can be explained through its lower section factor, as it can be observed in Table $4 \mathrm{a})\left(\mathrm{A}_{\mathrm{m}} / \mathrm{V}=55 \mathrm{~m}^{-1}\right)$. This bottom plate configuration exposes a lower surface to the fire per unit area and therefore its temperature rise is delayed.

\subsubsection{Effect of the slim-floor configuration}

The slim-floor configuration plays an important role in the fire performance of the composite beam. In order to investigate this effect, two different configurations, namely SFB and IFB, have been studied in this section. Two different options were considered in this case: an equivalent IFB section with a similar inertia and therefore similar room temperature capacity (IFB1), and an IFB section with the same steel area and thus same cost of material (IFB2). Using the commercially available IPE profiles, the solutions with a more approximate equivalence are those given in Table 5a). This table shows the section factor $\left(A_{m} / V\right)$, steel crosssection area $\left(A_{s}\right)$ and inertia $\left(I_{s}\right)$ together with the ultimate load $\left(N_{R d}\right)$ and sagging moment capacity at room temperature $\left(M_{R d}\right)$ of the different specimens studied.

The results of this analysis for the different load levels applied are given in Table 5b), where it can be seen that both IFB options produce lower fire resistance times than the SFB configuration. In the case of same room temperature capacity (IFB1) this finding occurs for all the load levels studied - although with a reduction of this difference for the lower load levels , while for the case IFB2 with the same steel area, the fire resistance of the SFB configuration is higher for the highest load levels studied but the difference decreases or even switches for the lower ones, where the failure time of IFB2 is higher. The enhanced performance observed in the SFB configuration as compared to the IFB configuration is due to the effect of the air gap 
between the bottom steel plate and lower flange, which delays the temperature rise along the web of the steel profile and therefore lengthens the loss of flexural capacity in fire.

In general, it can be observed that for the higher load levels, associated to lower fire exposure times, the increase obtained with the SFB configuration is quite significant (with up to a $50 \%$ increase at 0.8 load level), and this difference decreases progressively with the reduction of load level and the increase of the fire exposure until the capacities of both configurations are very similar, see Fig. 16. It can be therefore concluded that the thermal gap becomes less influential as the fire exposure time increases.

However, it should be noted that this comparison is performed in terms of relative load level (referred to the room temperature capacity of each specimen), but it is clear that in absolute terms the capacity of specimen IFB2 would be higher, as it presents a higher depth and thus a $126 \%$ higher capacity at room temperature.

\subsubsection{Effect of the concrete aggregate type}

Additionally, regarding to material properties, the concrete aggregate type was also analysed. The reference specimen SFB0 was calculated using calcareous aggregate for the concrete encasement. However, it was considered important to analyse the influence of other concrete aggregate types due to their different thermal and mechanical behaviour at elevated temperatures. Specifically, siliceous aggregate and lightweight concrete were taken into account. EN 1992-1-2 [22] provides full information about the different behaviour at elevated temperatures between siliceous and calcareous aggregate concrete. The main difference between these two types of aggregates comes from the strength reduction and thermal elongation at elevated temperatures, where concrete with calcareous aggregates shows a slower strength reduction with temperature and a lower thermal elongation. However, no differences are provided in EN 1992-1-2 [22] related to their thermal conductivity and specific heat. 
On the other hand, EN 1994-1-2 [5] provides information on the behaviour of lightweight concrete at elevated temperatures. In this case, both mechanical and thermal properties are modified. Explicitly, lightweight concrete shows lower thermal conductivity, specific heat and strength reduction than concrete with calcareous or siliceous aggregates. Therefore, a better fire performance is expected in this case.

Using the different types of concrete described above whilst maintaining the geometry and steel properties, two new specimens were generated: SFB3-(SIL) with $30 \mathrm{MPa}$ cylindrical strength for the concrete encasement but using siliceous aggregates and SFB4-(LC) with lightweight concrete of $30 \mathrm{MPa}$ cylindrical strength. The overall behaviour of these two specimens compared with the reference one (SFB0) using calcareous aggregate is shown in Fig. 17. Contrary to expectations, the use of siliceous aggregates or lightweight concrete do not provide any improvement in terms of the fire behaviour of the slim-floor beam. This low influence of the concrete type can be explained due to the fact that the bending behaviour of the composite beam at elevated temperatures is primarily governed by the fire performance of the steel parts placed at the bottom of the cross-section, which is in tension. These steel parts are directly exposed to the fire and therefore slightly affected by small differences in the thermal properties of the concrete encasement.

\subsubsection{Effect of the longitudinal reinforcement}

Finally, the effect of adding longitudinal reinforcement was analysed. Specifically, $2 \$ 20$ $\mathrm{mm}$ reinforcing steel bars with $500 \mathrm{MPa}$ yield strength were symmetrically placed $30 \mathrm{~mm}$ over the SFB lower steel flange on the longitudinal direction, see Fig. 18. The rest of the geometrical parameters were maintained equal to the reference specimen SFB0. Besides, two different concrete aggregate type were used for the concrete encasement: calcareous aggregate (SFB5) and lightweight concrete (SFB6). The results of the fire performance of these reinforced configurations are compared with the reference specimen in Fig. 19. It can be observed that due 
to the convenient location of the reinforcing bars within the section, protected from the direct exposure to the fire by the surrounding concrete, these configurations show a better fire behaviour for all applied load levels, allowing for an increase of the fire resistance between 1015 minutes. Additionally, the usage of lightweight concrete for the encasement results in an enhanced fire performance. As can be seen in Fig. 19, it lengthens up to 30 minutes the fire resistance as compared to the reference specimen SFB0 for a 0.3 load level. This improvement may be explained from the slower temperature rise of the reinforcing bars due to the lower conductivity of the surrounding lightweight concrete.

\section{DISCUSSION AND DESIGN RECOMMENDATIONS}

Through the results of the parametric studies presented in this paper, it is possible to provide a series of recommendations that may be useful for practitioners in the design of composite beams. It has been shown that a good strategy for enhancing the fire resistance of composite beams embedded in floors is to split the lower steel flange into two steel plates, generating the so-called SFB type. In this solution, a thermal resistance appears between the lower flange and the bottom plate that delays the temperature rise and therefore lengthens the fire response of the beam for the same load level, as compared to the IFB configuration.

However, this is valid only when the two equivalent beams present the same room temperature capacity. If the equivalence is made in terms of steel area, obviously the IFB configuration would have a higher depth and thus a higher room temperature capacity, leading also to a superior capacity in fire, since the inertia is optimized through the shape of the IPE profile.

In particular, for the SFB configuration, increasing the thickness of the bottom steel plate contributes to enhance further the fire resistance of the beam, due to the effect of the lower section factor that results in a delayed temperature field. 
Regarding the use of different types of concrete, the change from calcareous aggregates to siliceous aggregates does not provide any improvement in terms of fire behaviour, nor does the use of lightweight concrete when the beam is not reinforced. However, when using longitudinal reinforcement to help sustain the sagging moments in the fire situation, the advantageous thermal properties of lightweight concrete may help delay the temperature rise of the reinforcing bars, with the subsequent enhancement in terms of fire resistance.

\section{SUMMARY AND CONCLUSIONS}

This paper presented an advanced thermo-mechanical model for investigating the fire behaviour of composite beams embedded in floors - slim-floor beams -. A finite element model was developed, which was able to represent with good accuracy the behaviour of this novel typology by comparison with experimental tests. Specifically, two types of beam configuration were studied - IFB and SFB - combined with hollow core slabs as flooring system. As no specific fire tests on this solution exist to date, the validation was carried out in three stages: thermo-mechanical validation of the hollow core slab, thermo-mechanical validation of composite beams with other flooring system - such as profiled steel deck - and finally thermal validation of the SFB and IFB sections with hollow core slab. From the basis of a well validated numerical model, parametric studies were conducted, in order to analyse the influence of the different parameters of the slim-floor configuration. The effect of the bottom steel plate thickness was studied, as well as the configuration itself (IFB or SFB) and the use of different concrete types or longitudinal reinforcement. The most influencing parameter was found to be the slim-floor beam configuration, being observed that the SFB solution improves the fire resistance for the same load level applied as compared to the IFB configuration. Also, the use of reinforcing bars combined with lightweight concrete or the increase of the bottom plate thickness may contribute enhancing the fire resistance of slim-floor beams. These strategies 
may be regarded as good alternatives to applying external protection by means of intumescent coatings or fire resistant gypsum boards, with the related cost and material savings.

\section{ACKNOWLEDGEMENTS}

The authors would like to express their sincere gratitude to the Spanish "Ministerio de Economía y Competitividad" for the help provided through the Project BIA2015-67192-R and to the European Union through the FEDER funds.

\section{REFERENCES}

[1] Ellobody E. Nonlinear behaviour of unprotected composite slim floor steel beams exposed to different fire conditions. Thin-Walled Structures. 2011;49:762-71.

[2] Ma Z, Mäkeläinen P. Behavior of composite slim floor structures in fire. Journal of structural engineering New York, NY. 2000;126:830-7.

[3] Kim HJ, Kim HY, Park SY. An experimental study on fire resistance of slim floor beam. Applied Mechanics and Materials2011. p. 752-7.

[4] Kang H, Lee DH, Hwang JH, Oh JY, Kim KS, Kim HY. Structural Performance of Prestressed Composite Members with Corrugated Webs Exposed to Fire. Fire Technology. 2015.

[5] CEN. EN 1994-1-2, Eurocode 4: Design of composite steel and concrete structures. Part 1-2: General rules - Structural fire design. Brussels, Belgium: Comité Européen de Normalisation; 2005.

[6] Zaharia R, Franssen JM. Simple equations for the calculation of the temperature within the cross-section of slim floor beams under ISO Fire. Steel and Composite Structures. 2012;13:171-85.

[7] Cajot L-G, Gallois L, Debruyckere R, Franssen JM. Simplified design method for slim floor beams exposed to fire. Nordic Steel Construction Conference. Oslo, Norway2012.

[8] Espinos A, Romero ML, Hospitaler A, Pascual AM, Albero V. Advanced materials for concrete-filled tubular columns and connections. Structures. 2015;4:105-13.

[9] Hanus F, Zaganelli D, Cajot L-G, Braun M. Analytical methods for the prediction of fire resistance of "reinforced" slim floor beams. In: Sohn E, editor. EUROSTEEL 2017. Copenhagen, Denmark2017.

[10] Fellinger JHH, Twilt L. Fire resistance of slim floor beams. Composite Construction in Steel and Concrete III. Irsee, Germany: American Society of Civil Engineers; 1996. 
[11] Lawson RM, Mullet DL, Rackham JW. Design of asymetric 'Slimflor' beams using deep composite decking. Berkshire, U.K.: The Steel Construction Institute; 1997.

[12] Newman GM. Fire resistance of slim floor beams. Journal of Constructional Steel Research. 1995;33:87-100.

[13] ABAQUS. Abaqus/Standard Version 6.14 User's Manual: Volumes I-III. Pawtucket, Rhode Island: Hibbit, Karlsson \& Sorensen, Inc. 2014.

[14] Aguado JV, Albero V, Espinos A, Hospitaler A, Romero ML. A 3D finite element model for predicting the fire behavior of hollow-core slabs. Engineering Structures. 2016;108:12-27.

[15] Cicekli U, Voyiadjis GZ, Abu Al-Rub RK. A plasticity and anisotropic damage model for plain concrete. Int J Plast. 2007;23:1874-900.

[16] CEN. EN 1991-1-2, Eurocode 1: Actions on structures. Part 1-2. General actions actions on structures exposed to fire. Brussels, Belgium: Comité Européen de Normalisation; 2002.

[17] Both C, Fellinger JHH, Twilt L. Shallow floor construction with deep composite deck: From fire tests to simple calculation rules. Heron. 1997;42:145-58.

[18] Ellobody E. Composite slim floor stainless steel beam construction exposed to different fires. Engineering Structures. 2012;36:1-13.

[19] Aguado JV, Espinos A, Hospitaler A, Ortega J, Romero ML. Influence of reinforcement arrangement in flexural fire behavior of hollow core slabs. Fire Safety Journal. 2012;53:72-84.

[20] CEN. EN 1363-1:2012 Fire resistance tests. General Requirements. Brussels, Belgium: Comité Européen de Normalisation; 2012.

[21] CEN. EN 1993-1-2, Eurocode 3: Design steel structures. Part 1-2: General rules Structural fire design. Brussels, Belgium: Comité Européen de Normalisation; 2005.

[22] CEN. EN 1992-1-2, Eurocode 2: Design of concrete structures. Part 1-2: General rules - Structural fire design. Brussels, Belgium: Comité Européen de Normalisation; 2004. 
IFB-type A

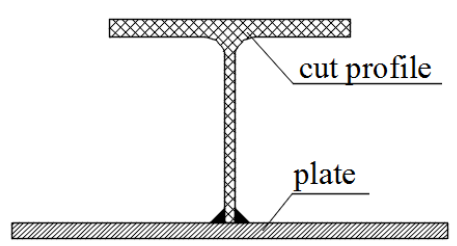

IFB-type B

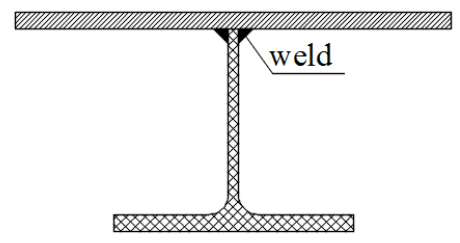

$S F B$

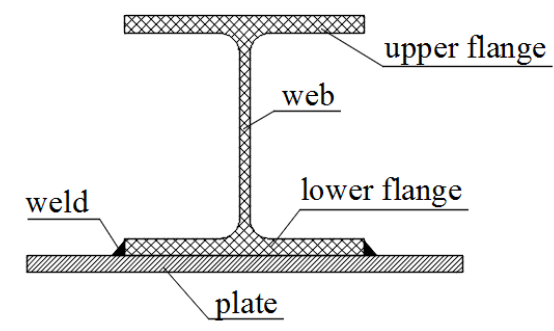

Fig. 1. IFB and SFB cross-section. 


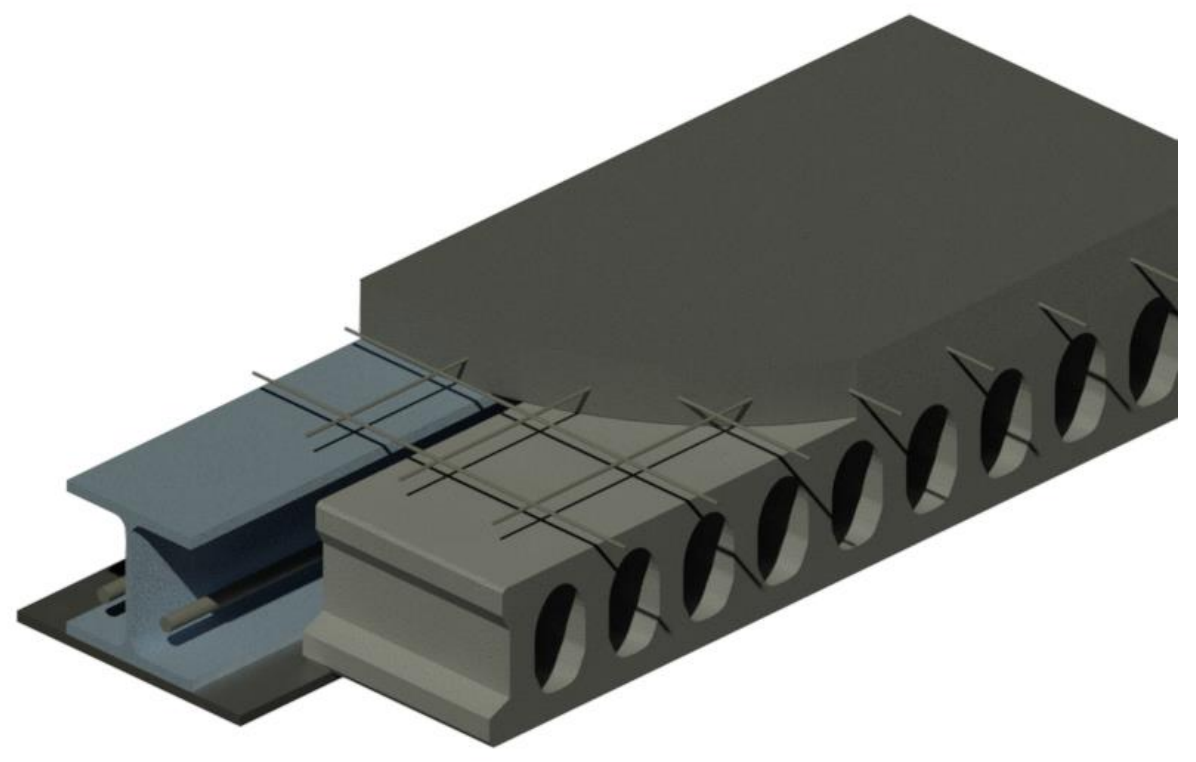

Fig. 2. Slim-floor with hollow core slabs. 3D general view 


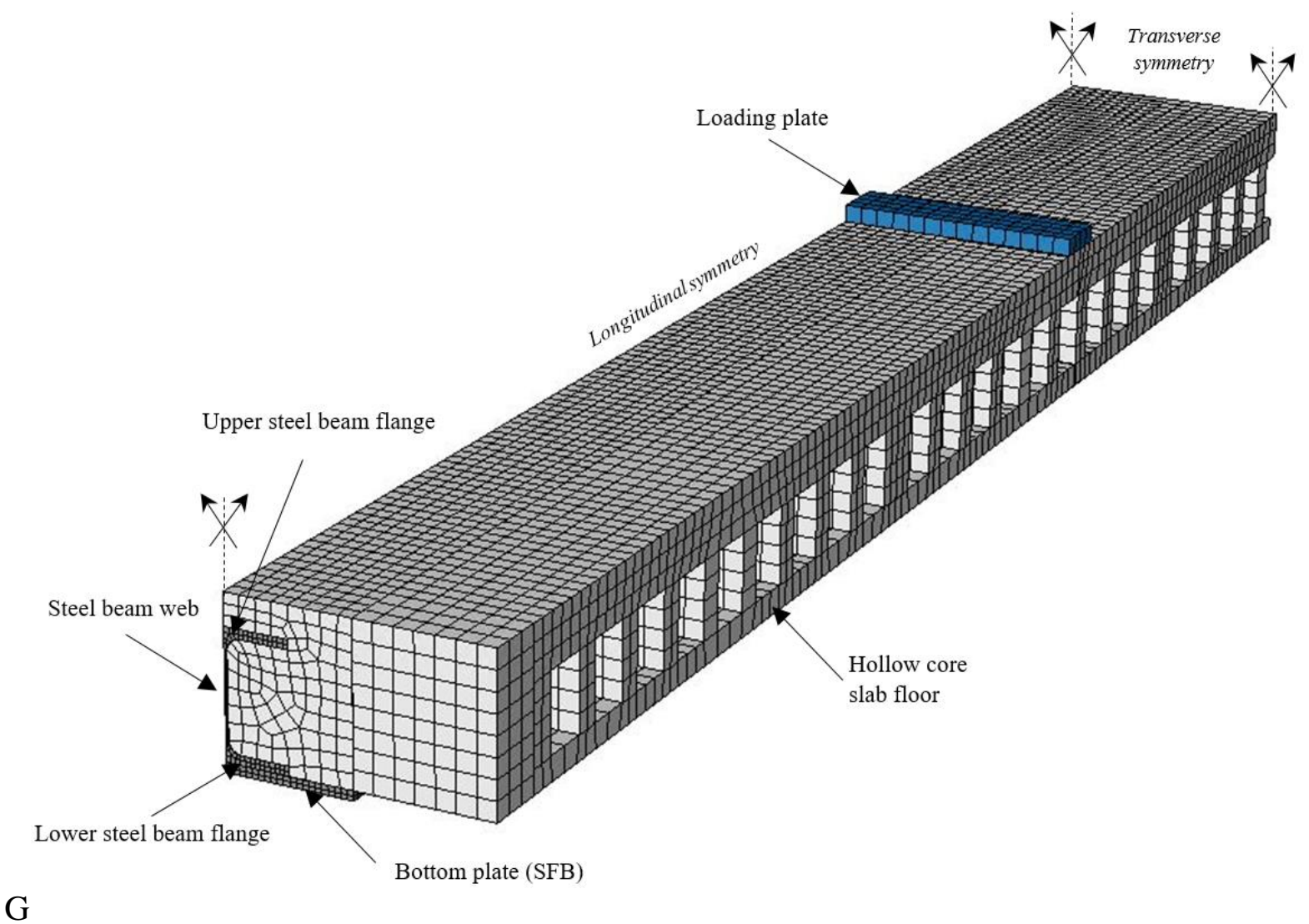

Fig. 3. Finite element mesh of SFB beam model 
- - - Gap conductance: $250 \mathrm{~W} / \mathrm{m}^{2} \mathrm{~K}$

- - - Gap conductance: $100 \mathrm{~W} / \mathrm{m}^{2} \mathrm{~K}+$ Gap radiation

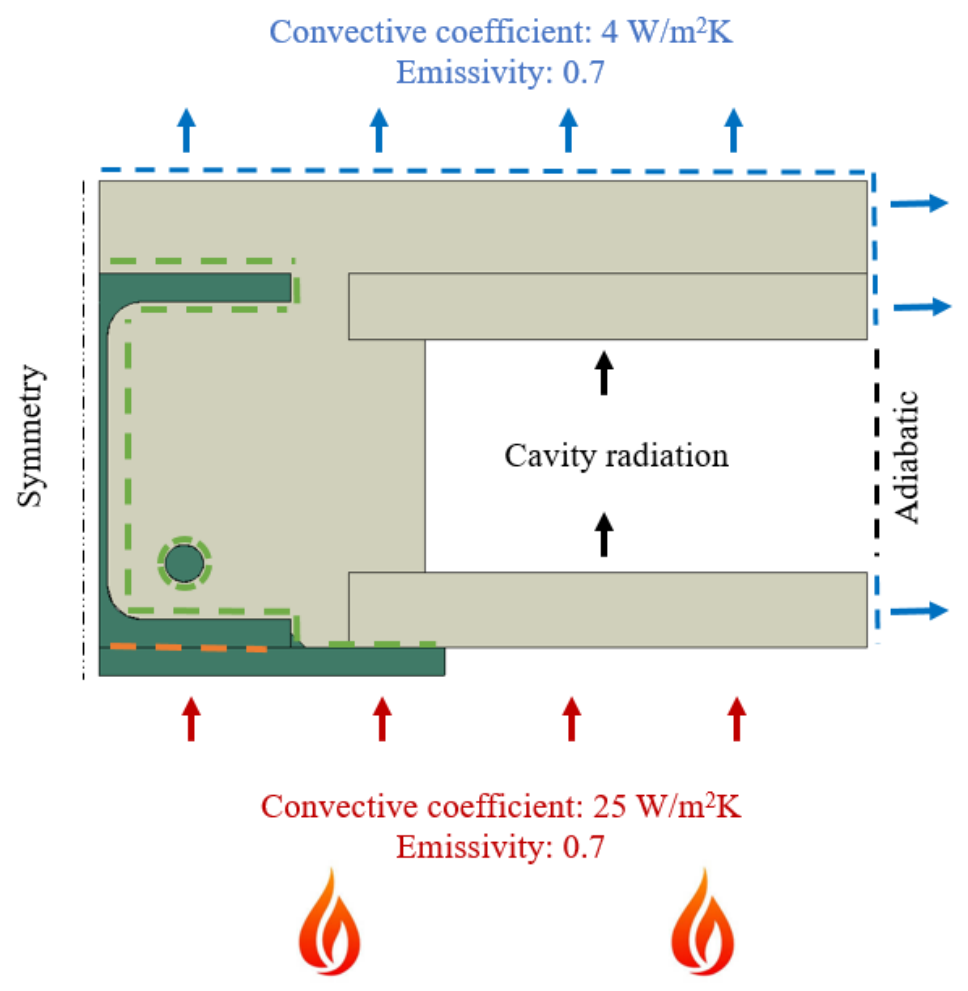

Fig. 4. SFB thermal model. Boundary conditions 

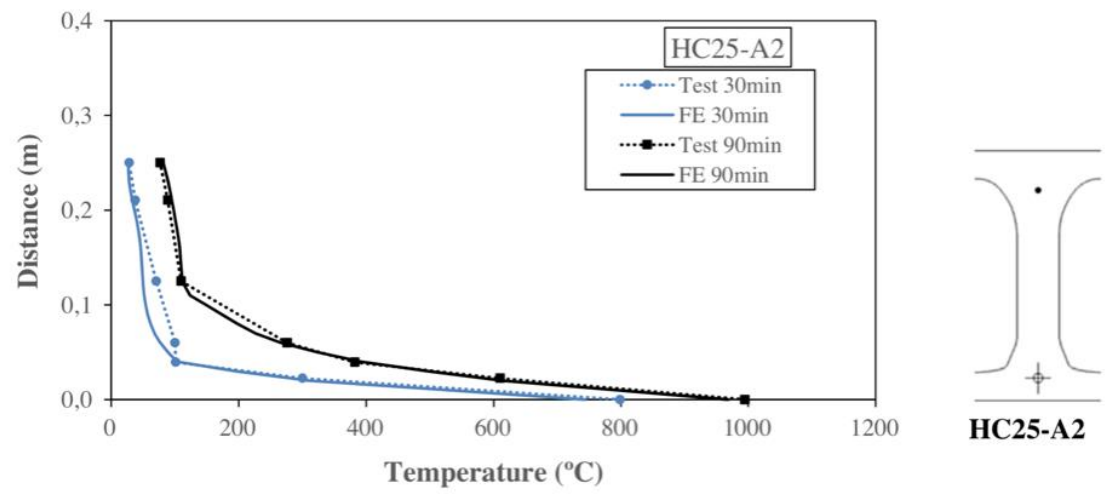

a) Temperature profiles.
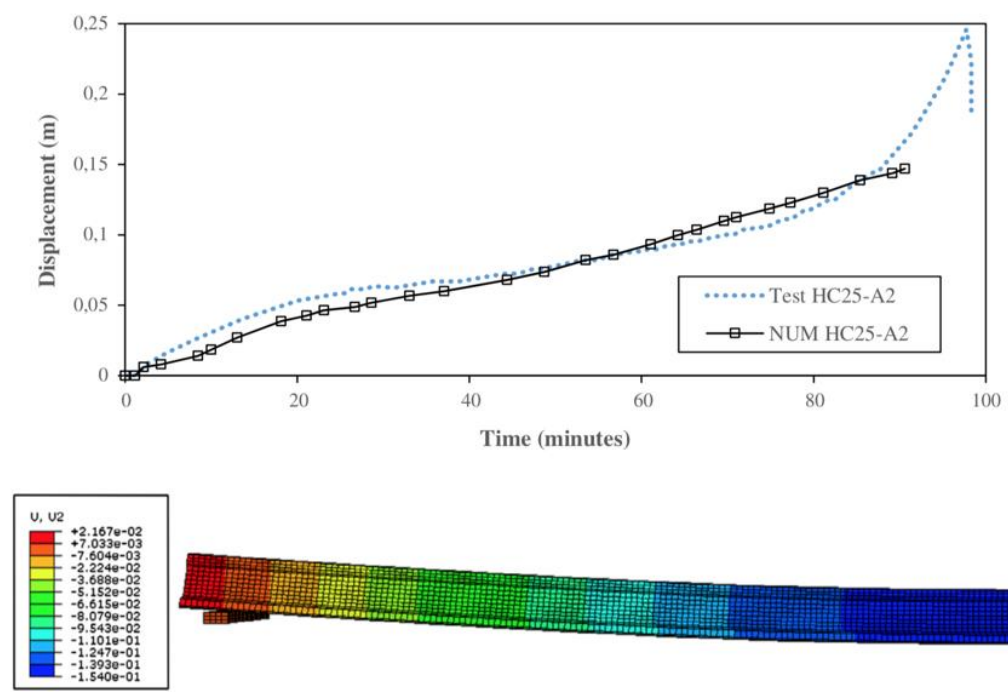

HC25-A2

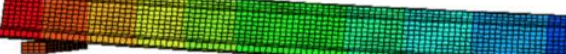

b) Vertical displacement.

Fig. 5. Hollow core slab model validation from previous work [14] 

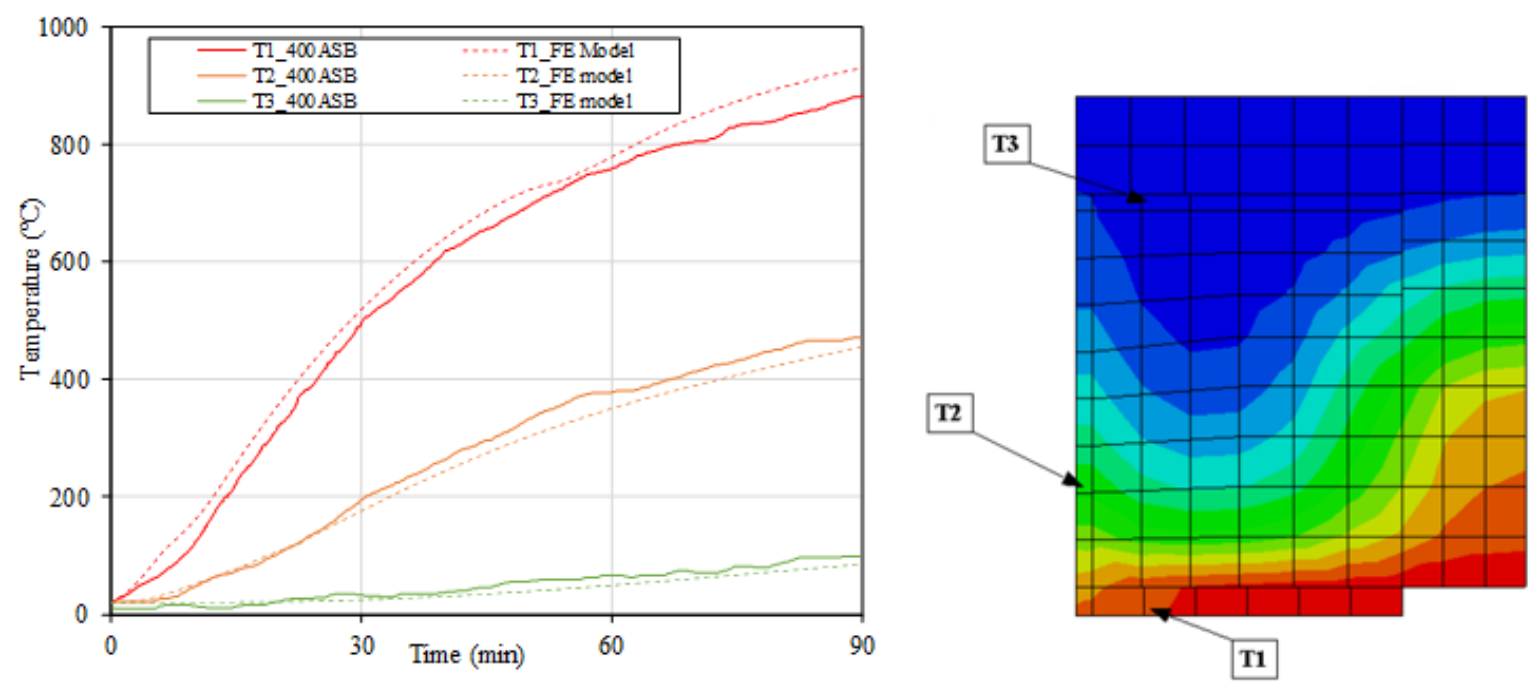

a) Temp-time evolution

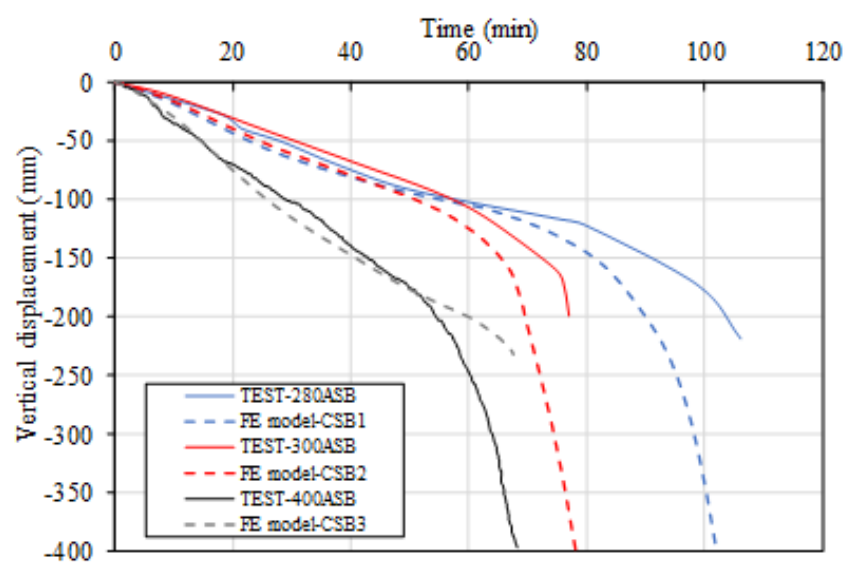

b) Vertical displacement-time evolution

Fig. 6. ASB tests validation $[2,11]$ 


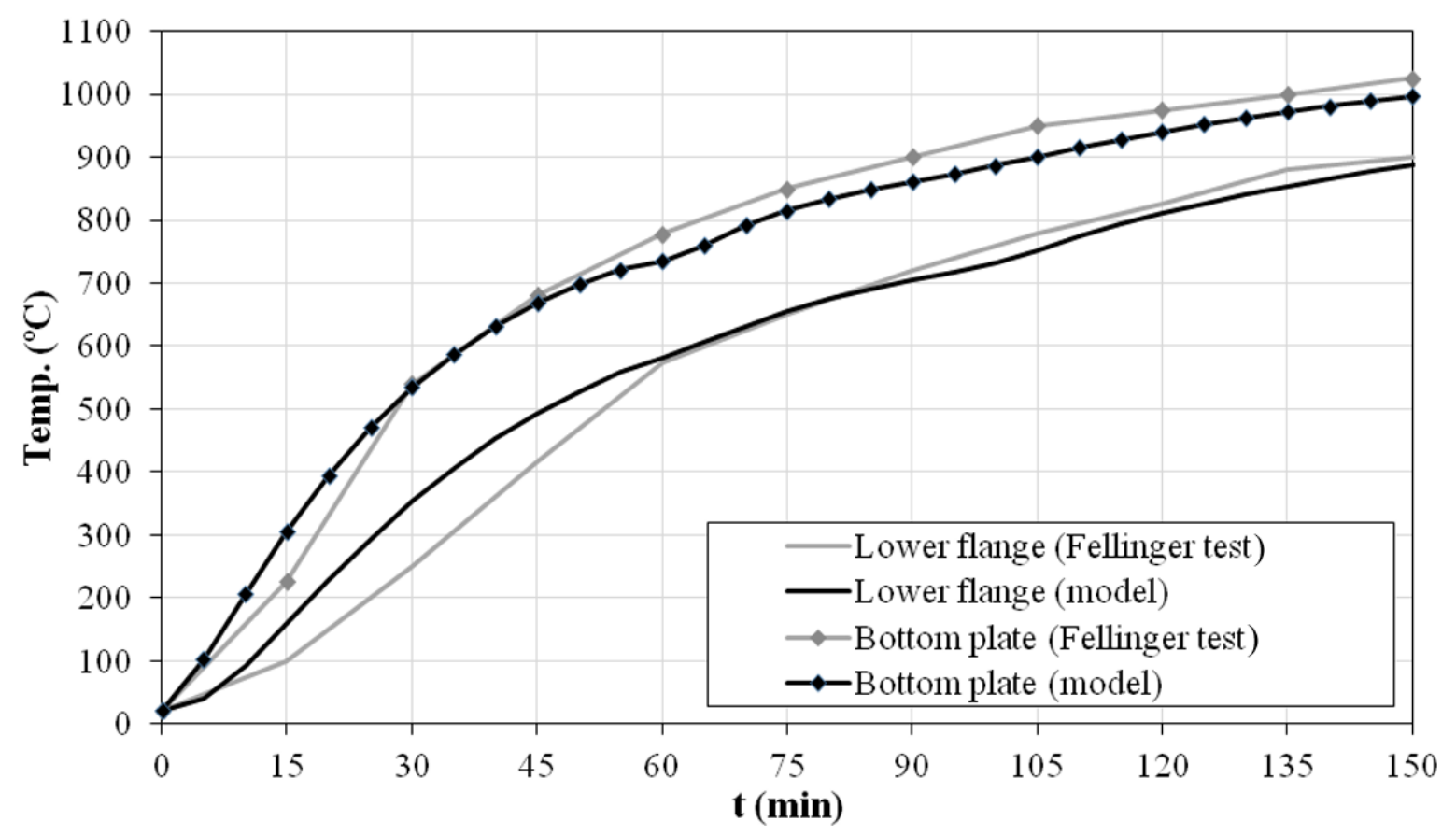

Fig. 7. Fellinger test [10] and model comparison 

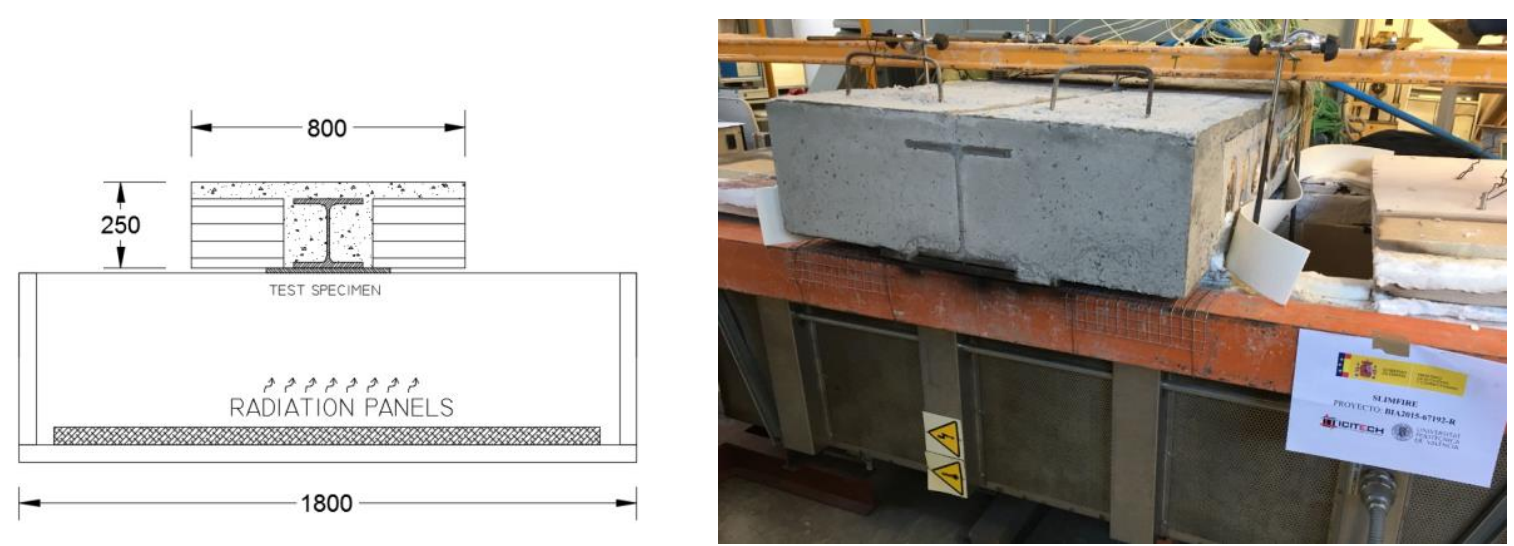

Fig. 8. Radiative furnace in ICITECH UPV testing facilities 

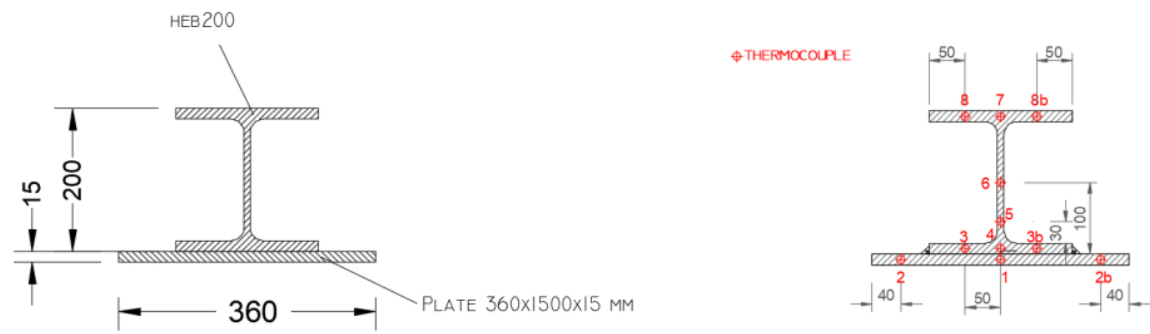

a) $\mathrm{SFB} 215-\mathrm{wC}$
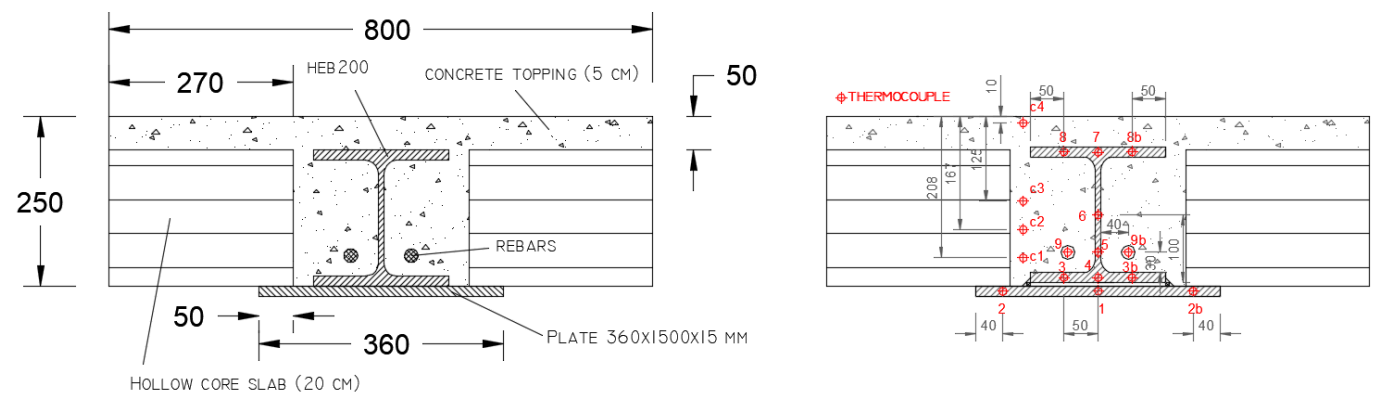

b) SFB215
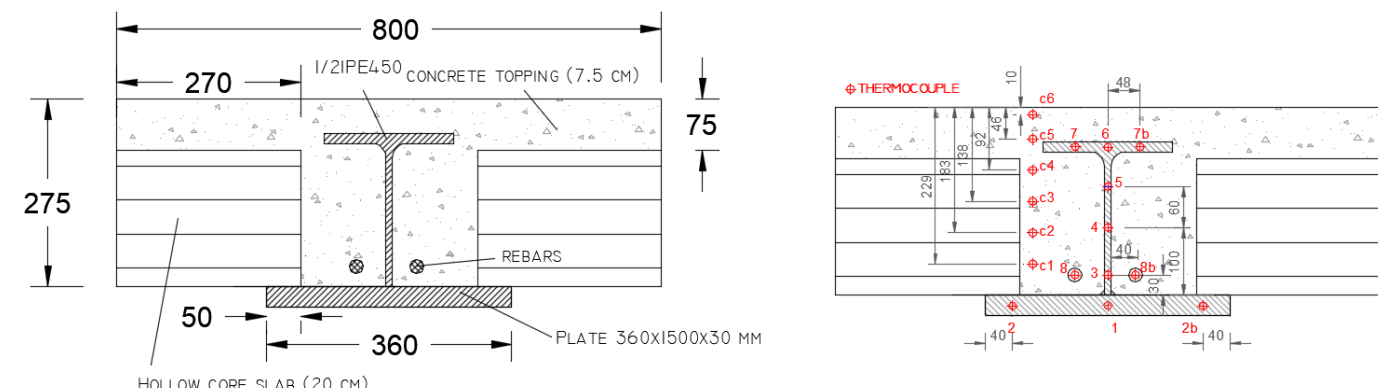

c) IFB255

Fig. 9. Geometry of the specimens tested 


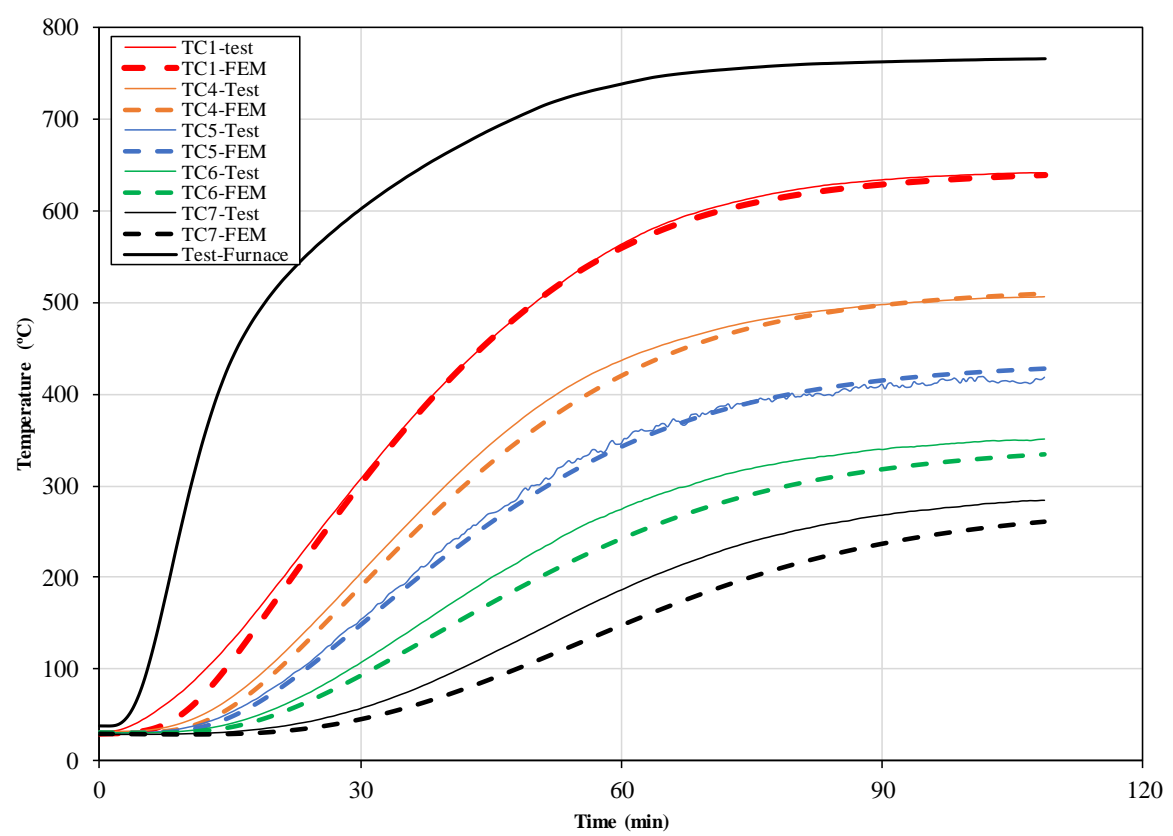

Fig. 10. SFB215-wC temperature validation 


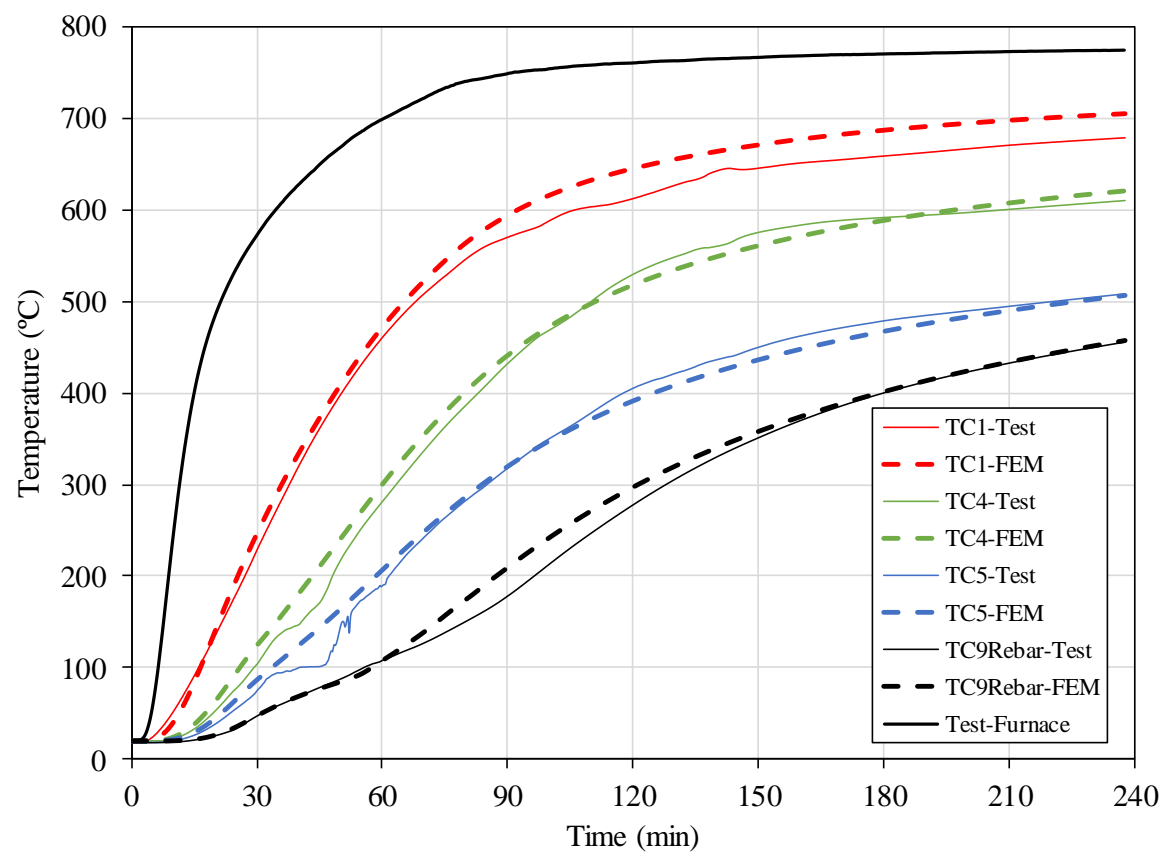

Fig. 11. SFB215 temperature validation 


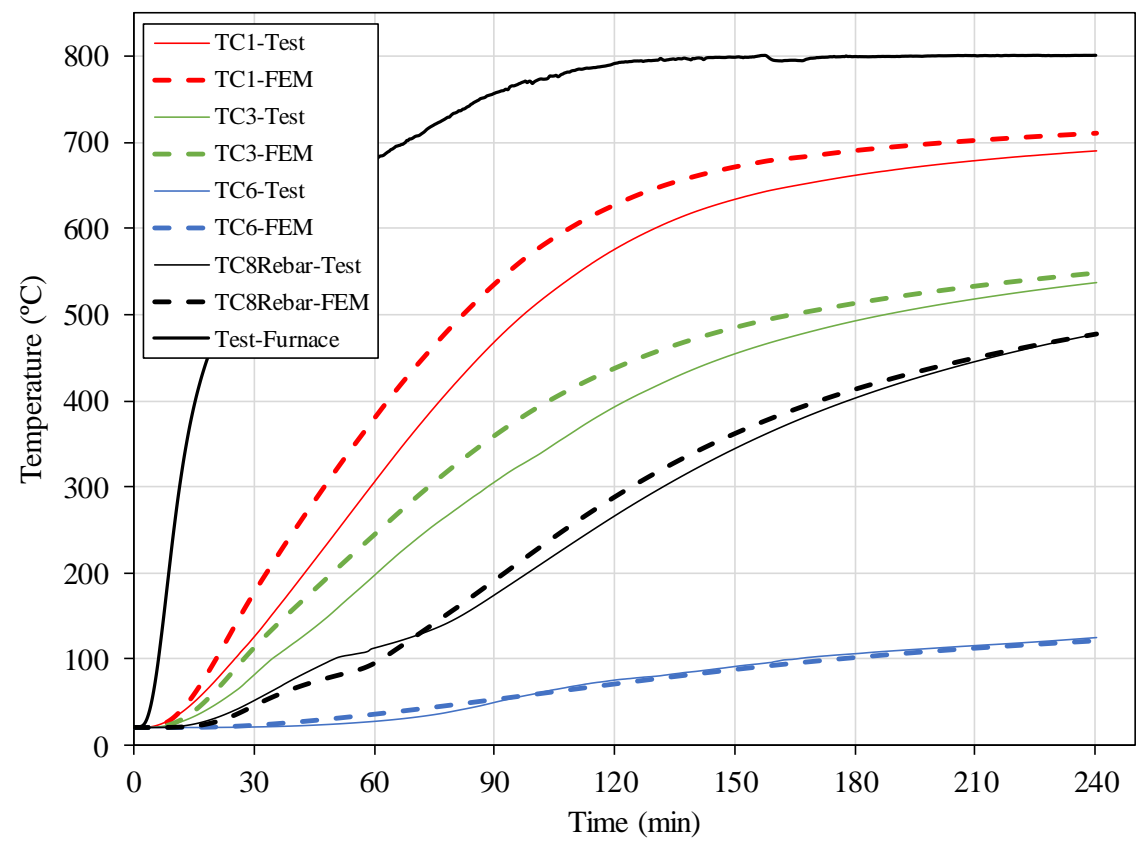

Fig. 12. IFB255 temperature validation 


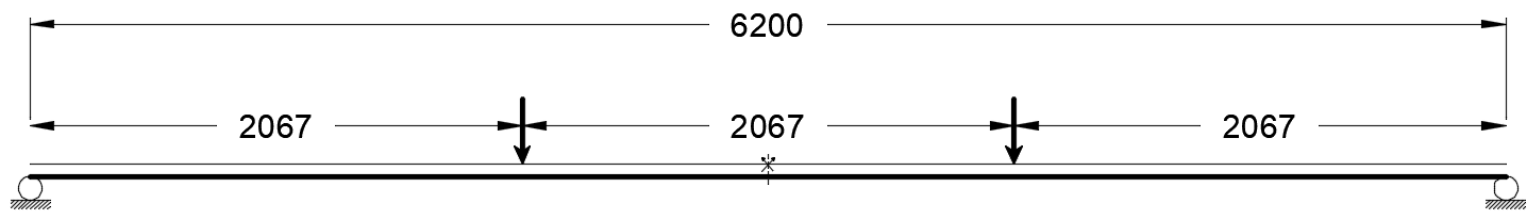

Fig. 13. Load pattern for parametric studies (distances in $\mathrm{mm}$ ) 
a)

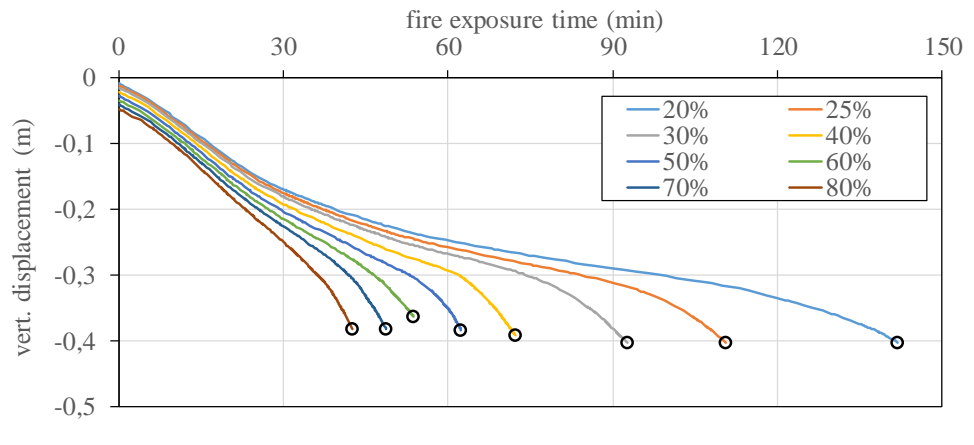

b)

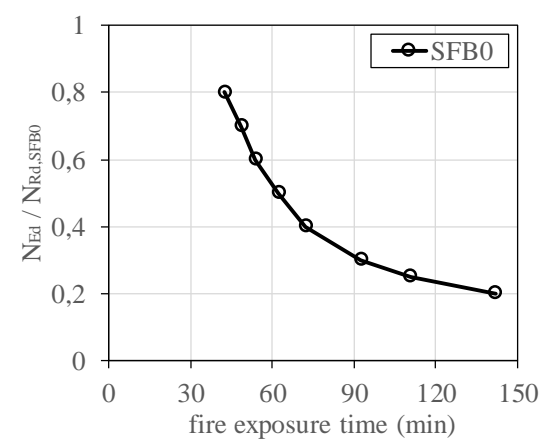

Fig. 14. Evolution of the fire behavior of the reference SFB0 beam: a) vertical displacement at mid-span versus time curves for different load levels, b) residual capacity versus time curve 


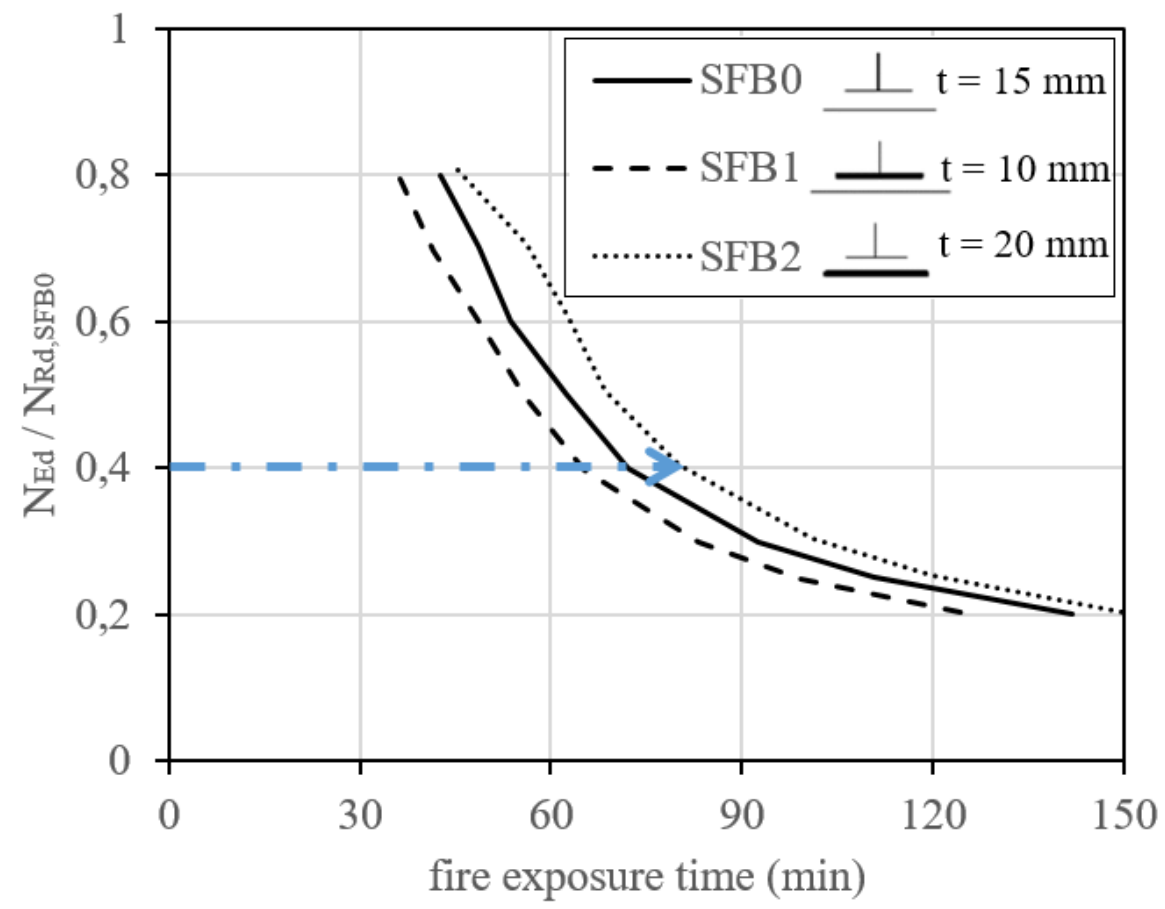

Fig. 15. Influence of the bottom plate thickness over the mechanical response of SFB section in fire 


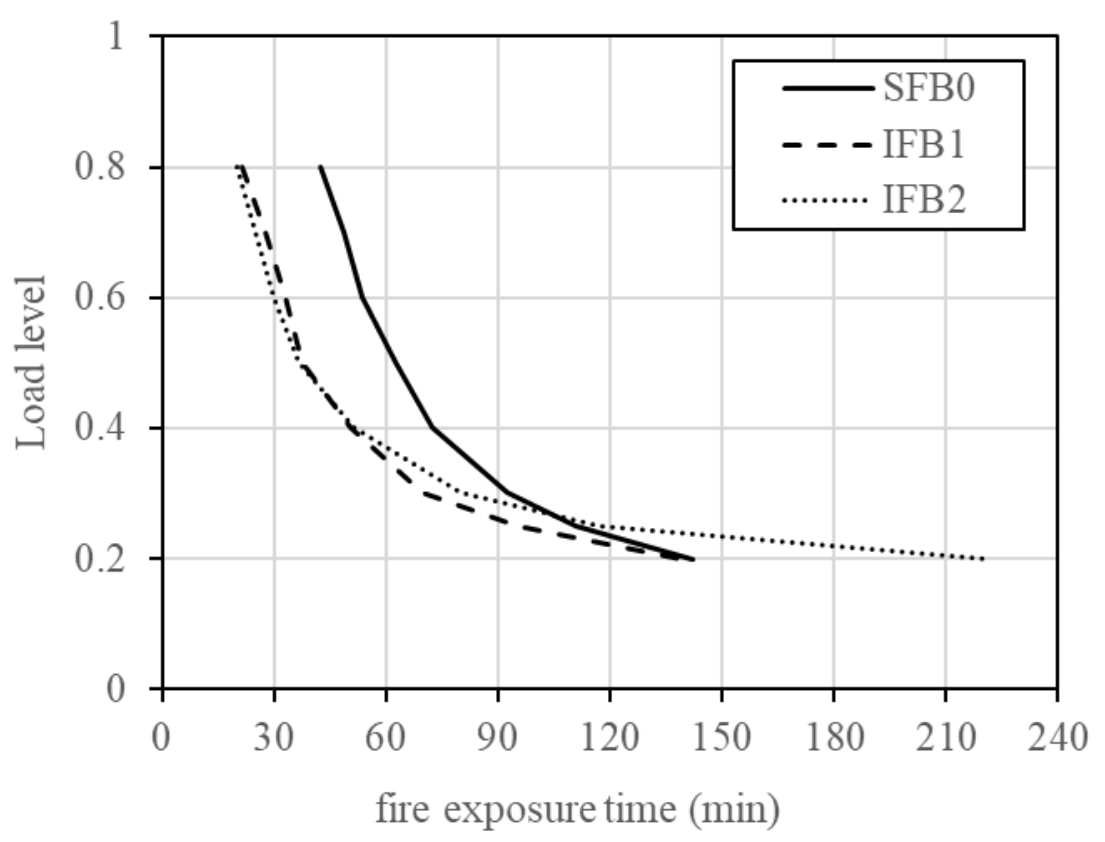

Fig. 16. Slim-floor configuration analysis. IFB vs. SFB mechanical response in fire 


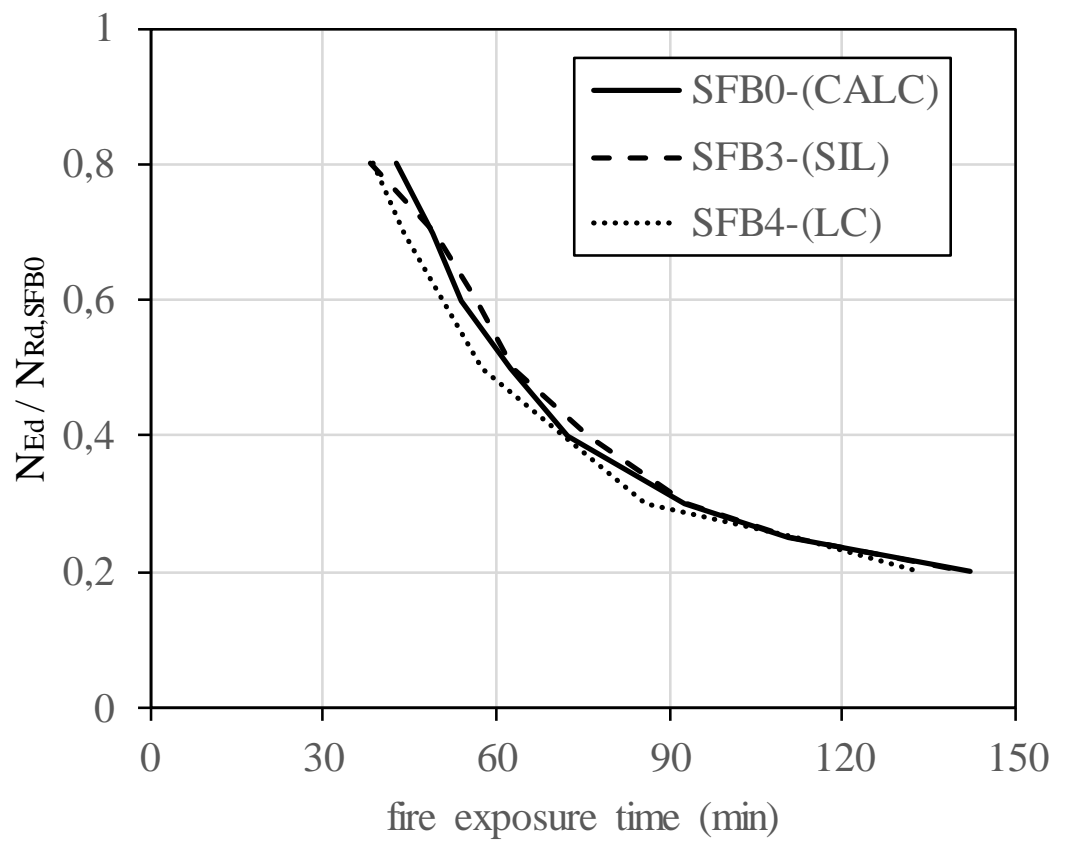

Fig. 17. Influence of the concrete aggregate over the mechanical response of SFB section in fire 


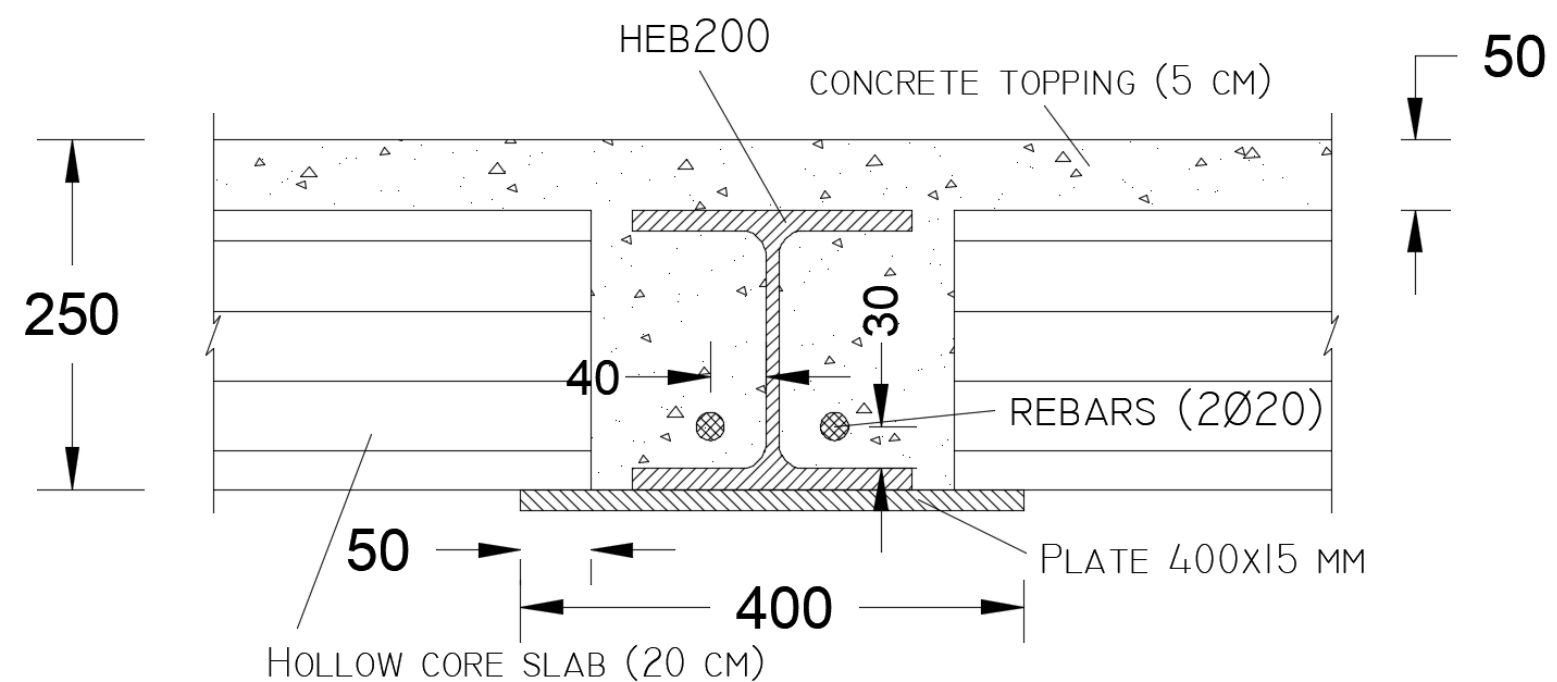

Fig. 18. SFB5-6 specimens with reinforcing bars 


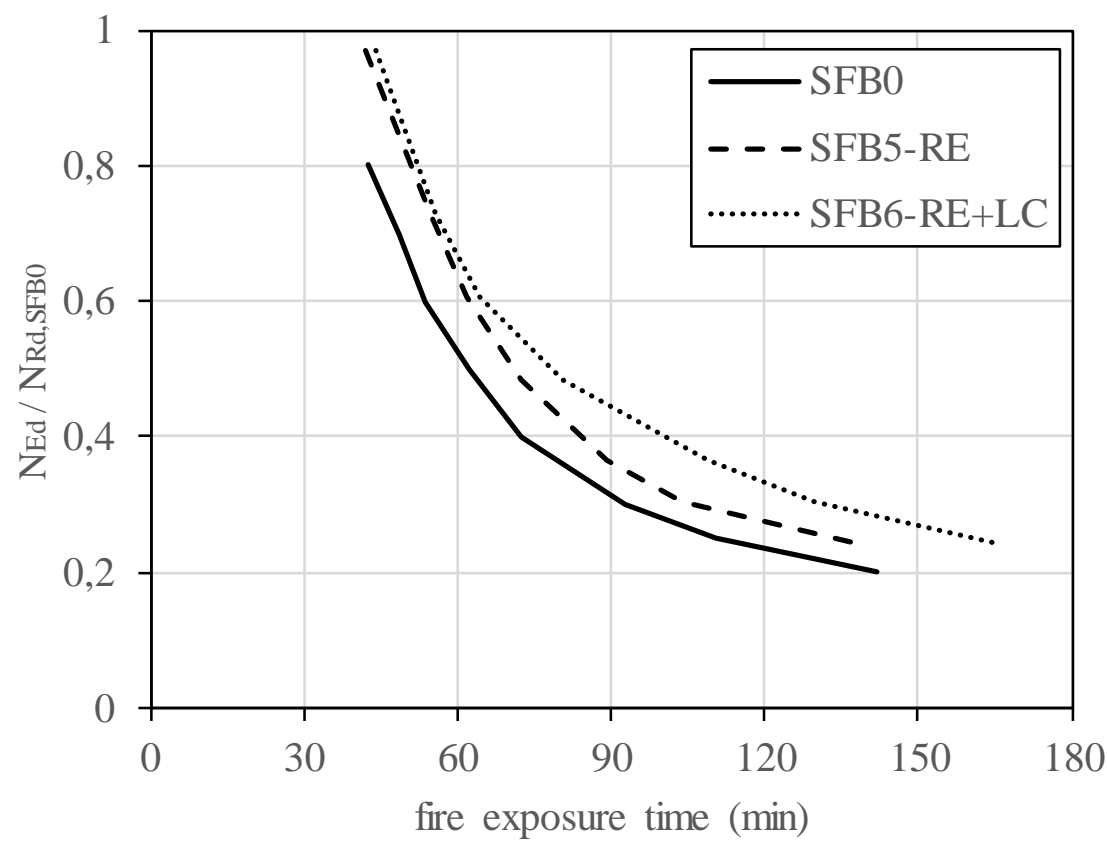

Fig. 19. Influence of the reinforcing bars inclusion over the mechanical response of SFB section in fire 
Table 1. Comparison between Newman [12] test $\mathrm{D}$ and predicted temperatures $\left({ }^{\circ} \mathrm{C}\right)$

\begin{tabular}{|c|c|c|c|c|c|c|c|c|c|c|c|}
\hline \multirow{3}{*}{ Test } & \multicolumn{6}{|c|}{30 minutes } & \multicolumn{5}{|c|}{60 minutes } \\
\hline & \multicolumn{2}{|c|}{$\begin{array}{c}\text { Newman } \\
\text { test }\end{array}$} & \multicolumn{4}{|c|}{ Model } & \multirow{2}{*}{\begin{tabular}{|c|}
$\begin{array}{c}\text { Newman } \\
\text { test }\end{array}$ \\
Plate Flange
\end{tabular}} & \multicolumn{4}{|c|}{ Model } \\
\hline & Plate & Flange & Plate & $\begin{array}{c}\xi \\
\text { (model/test) }\end{array}$ & Flange & $\begin{array}{c}\xi \\
(\text { model/test })\end{array}$ & & Plate & $\begin{array}{c}\xi \\
(\text { model/test) }\end{array}$ & Flange & $\begin{array}{c}\xi \\
\text { (model/test) }\end{array}$ \\
\hline $\mathrm{D}$ & 577 & 227 & 565 & 0.98 & 371 & 1.63 & $778 \quad 578$ & 767 & 0.99 & 581 & 1.00 \\
\hline
\end{tabular}


Table 2. Experimental thermal campaign

Test ID Description

\begin{tabular}{cc}
\hline SFB215 - wC & HEB 200 + Plate 360x15 (without concrete) \\
SFB215 & HEB 200 + Plate 360x15 + HCS 20 \\
IFB255 & $1 \frac{1}{2}$ IPE 450 + Plate 360x30 + HCS 20
\end{tabular}


Table 3. Parametric study

\begin{tabular}{cc}
\hline Parameter & cases \\
\hline Bottom plate thickness & $10-15-20 \mathrm{~mm}$ \\
Slim-floor configuration & SFB - IFB \\
Concrete aggregate & Calcareous - Siliceous - Lightweight concrete \\
Longitudinal bars & Unreinforced - Reinforced $(2 \phi 20)$ \\
\hline
\end{tabular}


Table 4. Bottom plate thickness analysis

a) Geometrical parameters and maximum capacities at room temperature

\begin{tabular}{|c|c|c|c|c|c|c|c|c|c|c|}
\hline ID & Description & $\begin{array}{l}\mathbf{A}_{\mathbf{m}} / \mathbf{V} \\
\left(\mathbf{m}^{-1}\right)\end{array}$ & $\begin{array}{c}A_{s} \\
\left(\mathbf{c m}^{2}\right)\end{array}$ & $\begin{array}{c}\left(\mathbf{A}_{\mathrm{s}}-\mathbf{A}_{\mathrm{s}, \mathrm{SFB} 0}\right) / \\
\mathbf{A}_{\mathrm{s}, \mathrm{SFB} 0}\end{array}$ & $\begin{array}{c}\mathbf{I}_{\mathrm{s}} \\
\left(\mathrm{cm}^{4}\right)\end{array}$ & $\begin{array}{c}\left(\mathbf{I}_{\mathbf{s}}-\mathbf{I}_{\mathbf{s}, \mathbf{S F B} \mathbf{0})}\right) / \\
\mathbf{I}_{\mathbf{s}, \mathbf{S F B} \mathbf{0}}\end{array}$ & $\begin{array}{c}\mathbf{N}_{\text {Rd }} \\
(\mathbf{k N})\end{array}$ & $\begin{array}{c}\left(\mathbf{N}_{\mathrm{Rd}}-\right. \\
\left.\mathbf{N}_{\mathrm{Rd}, \mathrm{SFB} 0}\right) / \\
\mathbf{N}_{\mathrm{Rd}, \mathrm{SFB} 0}\end{array}$ & $\begin{array}{c}\mathbf{M}_{\mathbf{R d}} \\
(\mathbf{k N} \cdot \mathbf{m})\end{array}$ & $\begin{array}{c}\left(\mathbf{M}_{\mathrm{Rd}}-\right. \\
\left.\mathbf{M}_{\mathrm{Rd}, \mathrm{SFB} 0}\right) / \\
\mathbf{M}_{\mathrm{Rd}, \mathrm{SFB} 0}\end{array}$ \\
\hline SFB0 & HEB200+\#400×15 & 71.67 & 138.1 & - & 9626 & - & 163.7 & - & 338.3 & - \\
\hline SFB1 & HEB200+\#400×10 & 105 & 118.1 & $-14.48 \%$ & 8616 & $-10.50 \%$ & 162.7 & $-0.59 \%$ & 336.3 & $-0.59 \%$ \\
\hline SFB2 & HEB $200+\# 400 \times 20$ & 55 & 158.1 & $+14.48 \%$ & 10504 & $+9.12 \%$ & 165.2 & $+0.89 \%$ & 341.3 & $+0.89 \%$ \\
\hline
\end{tabular}

b) Results of the parametric study for different load levels

\begin{tabular}{|c|c|c|c|c|c|c|c|c|c|c|}
\hline ID & $\begin{array}{c}\mu \\
(\%)\end{array}$ & $\begin{array}{c}\mathbf{t} \\
(\mathbf{m i n})\end{array}$ & ID & $\begin{array}{l}\mu \\
\%\end{array}$ & $\begin{array}{c}\mathbf{t} \\
(\mathbf{m i n})\end{array}$ & & ID & $\begin{array}{c}\mu \\
(\%)\end{array}$ & $\begin{array}{c}\mathbf{t} \\
(\mathbf{m i n})\end{array}$ & $\begin{array}{c}(\mathbf{t}-\mathbf{t}, \mathbf{S F B} \mathbf{0}) / \\
\mathbf{t}, \mathbf{S F B} 0\end{array}$ \\
\hline & & & & & & & & 0.8 & & \\
\hline & & 48.75 & & 0.7 & & & & 0.7 & 41.56 & \\
\hline & 0.6 & 53.72 & & 0.6 & 48.85 & & & 0.6 & 48.85 & \\
\hline & 0.5 & 62.40 & & 0.5 & & & & 0.5 & 55.93 & \\
\hline SFB0 & 0.4 & 72.26 & SFB1_0.4 & 0.4 & 65.24 & -9.7 & & 0.4 & 65.24 & \\
\hline SFB0_0. & 0.3 & 92.58 & SFB1_0.3 & 0.3 & 3.27 & -10.0 & 0.3 & 0.3 & 83.27 & \\
\hline SFB0_0.25 & 0.25 & 110.65 & & 0.25 & 99.17 & $-10.38 \%$ & SFB2_0.25 & 0.25 & 99.17 & \\
\hline SFB0_0.2 & 0.2 & 141.95 & & 0.2 & 127.04 & $-10.50 \%$ & SFB2_0.2 & 0.2 & 127.04 & $+6.63 \%$ \\
\hline
\end{tabular}


Table 5. Slim-floor configuration analysis

a) Geometrical parameters and maximum capacities at room temperature

\begin{tabular}{|c|c|c|c|c|c|c|c|c|c|c|}
\hline ID & Description & $\begin{array}{l}\mathbf{A} \mathbf{m} / \mathbf{V} \\
\left(\mathbf{m}^{-1}\right)\end{array}$ & $\begin{array}{c}\mathbf{A}_{\mathrm{s}} \\
\left(\mathrm{cm}^{2}\right)\end{array}$ & $\begin{array}{c}\left(\mathbf{A}_{\mathrm{s}}-\mathbf{A}_{\mathrm{s}, \mathrm{SFB} 0}\right) / \\
\mathbf{A}_{\mathrm{s}, \mathrm{SBB} 0}\end{array}$ & $\begin{array}{c}\mathbf{I s}_{\mathrm{s}} \\
\left(\mathrm{cm}^{4}\right)\end{array}$ & $\begin{array}{c}\left(\mathbf{I}_{\mathrm{s}}-\mathbf{I}_{\mathrm{s}, \mathrm{SFB} \mathbf{0})}\right) / \\
\mathbf{I}_{\mathrm{s}, \mathrm{SFB} \mathbf{0}}\end{array}$ & $\begin{array}{l}\mathbf{N}_{\text {Rd }} \\
(\mathbf{k N})\end{array}$ & $\begin{array}{c}\left(\mathbf{N}_{\mathrm{Rd}}-\right. \\
\left.\mathbf{N}_{\mathrm{Rd}, \mathrm{SFB} 0)}\right) / \\
\mathbf{N}_{\mathrm{Rd}, \mathrm{SFB} 0}\end{array}$ & $\underset{(\mathbf{k N} \cdot \mathbf{m})}{\mathbf{M}_{\mathbf{R d}}}$ & $\begin{array}{c}\left(\mathbf{M}_{\mathbf{R d}}-\right. \\
\mathbf{M}_{\mathrm{Rd}, \mathrm{SFB} 0)} / \\
\mathbf{M}_{\mathbf{R d}, \mathrm{SFB} 0}\end{array}$ \\
\hline SFB0 & HEB200+\#400×15 & 71.67 & 138.1 & - & 9626 & - & 163.7 & - & 338.3 & - \\
\hline IFB1 & 212mmIPE450+\#400×15 & 71.67 & 108.2 & $-21.66 \%$ & 9692 & $+0.68 \%$ & 171.4 & $+4.70 \%$ & 354.2 & $+4.70 \%$ \\
\hline IFB2 & 1/2IPE600+\#400×15 & 71.67 & 138.0 & $-0.07 \%$ & 24866 & $+158.31 \%$ & 370.3 & $+126.22 \%$ & 765.4 & $+126.22 \%$ \\
\hline
\end{tabular}

b) Results of the parametric study for different load levels

\begin{tabular}{ccccccccccc}
\hline ID & $\begin{array}{c}\boldsymbol{\mu} \\
(\boldsymbol{\%})\end{array}$ & $\begin{array}{c}\mathbf{t} \\
(\mathbf{m i n})\end{array}$ & ID & $\begin{array}{c}\boldsymbol{\mu} \\
(\boldsymbol{\%})\end{array}$ & $\begin{array}{c}\mathbf{t} \\
(\mathbf{m i n})\end{array}$ & $\begin{array}{c}(\mathbf{t}-\mathbf{t}, \text {,SFB0 }) / \\
\mathbf{t} \text { SFB0 }\end{array}$ & ID & $\begin{array}{c}\boldsymbol{\mu} \\
(\boldsymbol{\%})\end{array}$ & $\mathbf{t}(\mathbf{m i n})$ & $\begin{array}{c}(\mathbf{t}-\mathbf{t}, \text { SFB0 }) / \\
\mathbf{t}, \text { SFB0 }\end{array}$ \\
\hline SFB0_0.8 & 0.8 & 42.53 & IFB1_0.8 & 0.8 & 21.41 & $-49.66 \%$ & IFB2_0.8 & 0.8 & 19.96 & $-53.08 \%$ \\
SFB0_0.7 & 0.7 & 48.75 & IFB1_0.7 & 0.7 & 27.83 & $-42.91 \%$ & IFB2_0.7 & 0.7 & 24.87 & $-48.97 \%$ \\
SFB0_0.6 & 0.6 & 53.72 & IFB1_0.6 & 0.6 & 32.99 & $-38.58 \%$ & IFB2_0.6 & 0.6 & 29.79 & $-44.54 \%$ \\
SFB0_0.5 & 0.5 & 62.40 & IFB1_0.5 & 0.5 & 37.32 & $-40.20 \%$ & IFB2_0.5 & 0.5 & 36.68 & $-41.22 \%$ \\
SFB0_0.4 & 0.4 & 72.26 & IFB1_0.4 & 0.4 & 50.39 & $-30.27 \%$ & IFB2_0.4 & 0.4 & 51.33 & $-28.96 \%$ \\
SFB0_0.3 & 0.3 & 92.58 & IFB1_0.3 & 0.3 & 69.72 & $-24.69 \%$ & IFB2_0.3 & 0.3 & 79.89 & $-13.70 \%$ \\
SFB0_0.25 & 0.25 & 110.65 & IFB1_0.25 & 0.25 & 95.03 & $-14.11 \%$ & IFB2_0.25 & 0.25 & 117.10 & $5.83 \%$ \\
SFB0_0.2 & 0.2 & 141.95 & IFB1_0.2 & 0.2 & 139.34 & $-1.83 \%$ & IFB2_0.2 & 0.2 & 221.94 & $56.35 \%$ \\
\hline
\end{tabular}

